\title{
الأسلحة فى الفن الصخري بالمملكة العربية السعودية
}

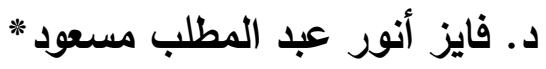

يشتمل الفن الصخري على رسوم ونقوش قام إنسان ما قبل الكتابة بتنفيذها على الصخور لموضوعات متعددة فى حياته منها على سبيل

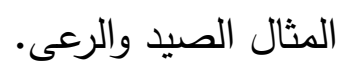

ويطلق مسمى الرسوم الصخرية في المملكة العربية السعودية من قِبل كثير من العلماء على كل من المناظر المرسومة والمنقوشة - أي مناظر الرسوم والنقوش - وذللك تمييزًا عن الكتابات القديمة والتى تُعرف باسم النقوش.

ويذهب مجيد خان إلى أن المملكة العربية السعودية تُعد دولة غنية بتراثها الحضاري الذي يرجع إلى ما قبل الكتابة كمكتشفات فى شكل

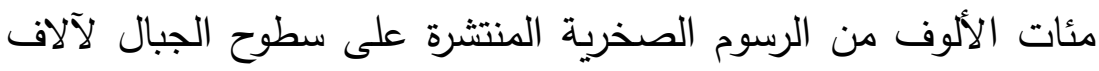

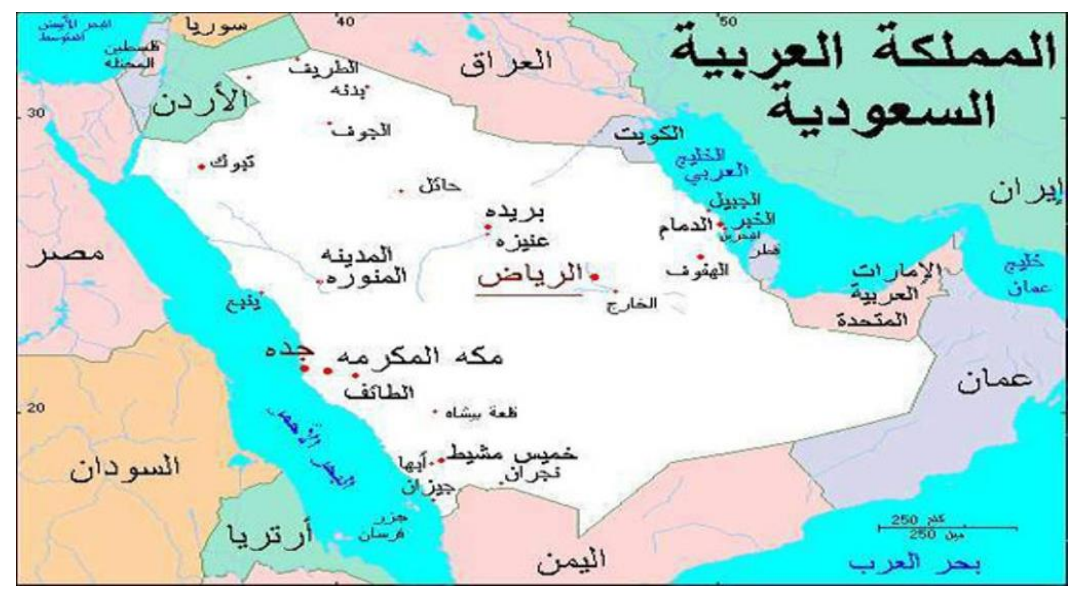

مواقع الفن الصخرى بالمملكة العربية السعودية

http://www.almrsal.com/post/209762

* مدرس التاريخ القديم- كلية الآداب - جامعة دمنهور

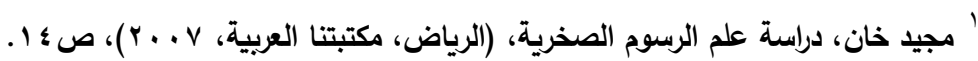


وبالنسبة لبداية معرفة إنسان ما قبل الكتابة للرسوم الصخرية في

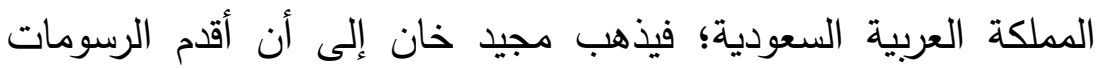
الموجودة تعود للعصر الحجرى (10- r ا ألف سنة قبل الميلاد)، وقد تم تحديد تأريخ هذه الرسومات من خلال الأدوات الحجرية التى وجدت فى تلك المواقع فى كلوه وتبوك وخيير فى المنطقة الثمالية الغربية للمملكة التى وجدت فيها رسومات كثيرة لحيوانات غير واضحة'، بينما

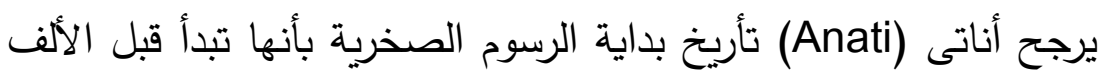

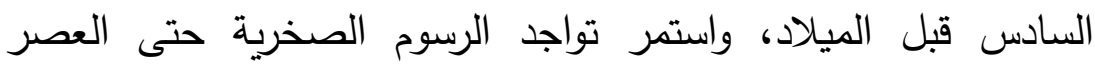
الإسلامي، وجاء تقسيمه كالآتى:

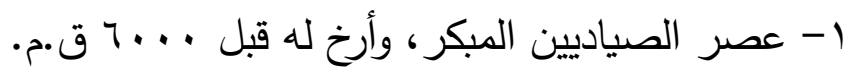
r- عصر الصياديين والرعاة

- عصر الصيد والرعي القديم، وأرخ له من . . . . - . . . . . ق ق.م.

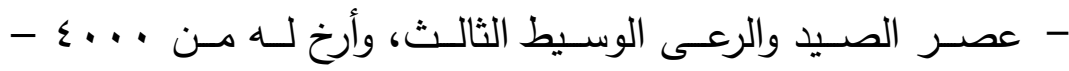

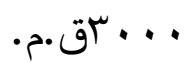

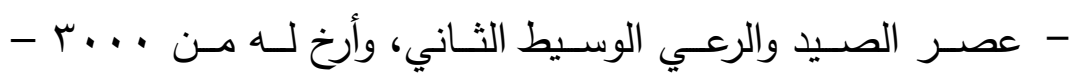
•....

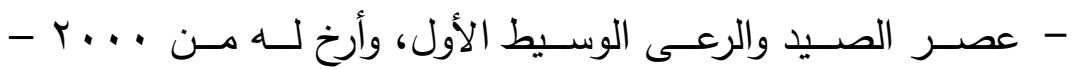

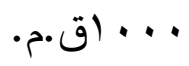
- عصر الصيد والرعي الحيث، وأرخ له من . . ب أ - . . . . مق.م.

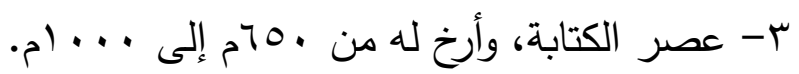

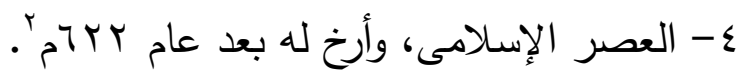

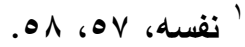

2 Anati. E., Rock Art in Central Arabia, vol.1 (1968), p.160; Červíček. P., Some African Affinities of Arabian Rock Art, Rassegna di Studi Etiopici, Vol. 27 (1978-1979), p.8 


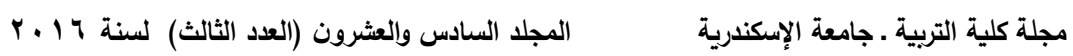

ويذهب مجيد خان إلى أن الأسلوب الذي اتبعه أناتي (Anati) فى

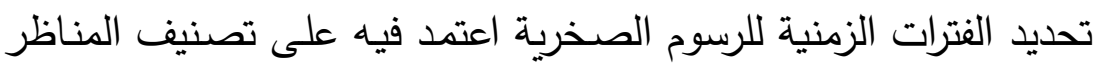
فقط، وهو الأمر الذي جعل مجيد خان يَعُد تقسيم أناتي (Anati) للفترات

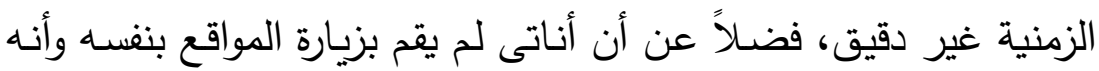

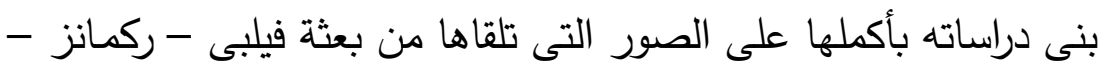

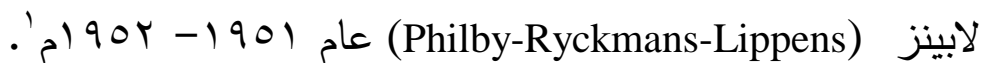
ولذلك ذهب محم عبدالمنعم إلى أنه طالما لا توجد تواريخ قطعية موثوق بها للرسوم الصخرية بالمملكة العربية السعودية، كان من الأجدى الته توصيف الرسوم الصخرية كل بحسب منطقتها الجغرافية، ومن ثم تقييم نتائج الدراسة لكل المناطق الجغرافية المختلفة. وهذا النمط من التصنيف الإقليمي يسهل متابعة التطورات وأوجه التباين والتماثل لفن الرسوم الصخرية للأقاليم المختلفة للمملكة؛.

ويرى مسفر الخثعىى أن مجيد خان صنف رسومات شمال المملكة العربية السعودية إلى فترة ما قبل الكتابة دون تقديم مبررات مقنعة،

${ }^{1}$ Majeed Khan, A Critical Review of Rock Art Studies in Saudi Arabia, East and West, Vol. 48, No. 3/4 (December 1998), pp.427-428;

مجيد خان حسن خان، دراسة نقدية عن كتب أناتي فى الرسوم الصخرية بالمملكة

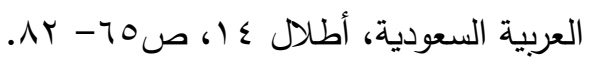

لَمحم عبدالمنعم، آثار ما قبل التاريخ وفجره في الملكة العربية السعودية، ترجمة:

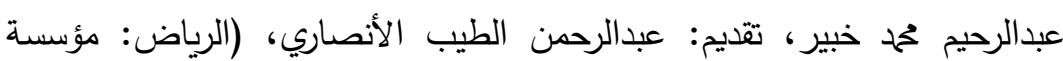

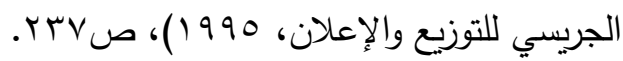


ويعتقد - مسفر - أن كثيرًا من الرسوم الصخرية تعود إلى الفترات

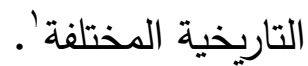

ويعلل عبدالرحمن الكباوى بأنه لا يمكن الوصول إلى تحديد مطلق

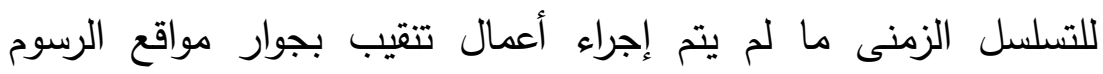

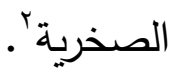

ويتضح مما سبق أنه لم يوجد تأريخ متفق عليه لـناظر الرسوم

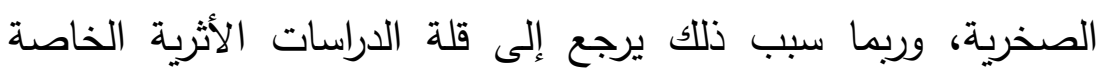
بالرسوم الصخرية، وكذلك الحفائر الأثرية بجوار تلك المناظر .

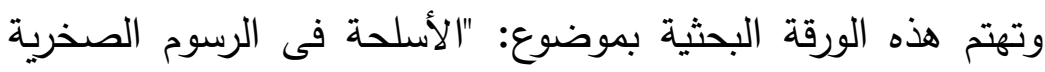

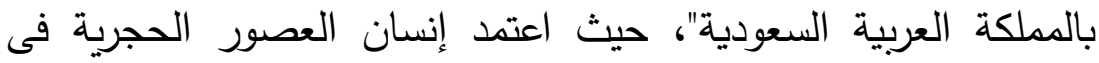
تحصيل غذائه بشكل أساسي على لحوم الحيوانات، وتطلب ذلك تصنيع أدوات حجرية يستخدمها فى صيدها؟، وكانت أول الأدوات التي

'مسفر بن سعد الخثعمى، الرسوم الصخرية فى مدينة أبها وضواحيها دراسة توثيقية

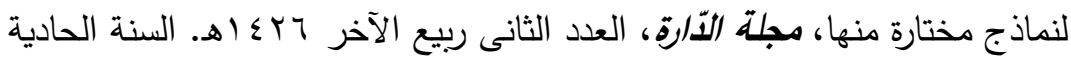

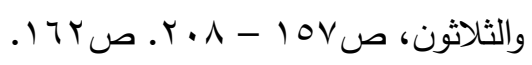

' عبدالرحمن الكباوى، مجيد خان، عبدالرحمن الزهرانى، تقرير مبدئى عن المرحلة

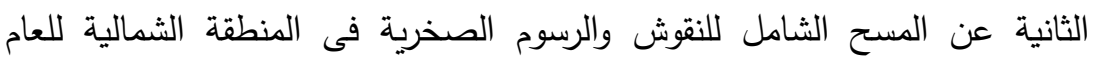

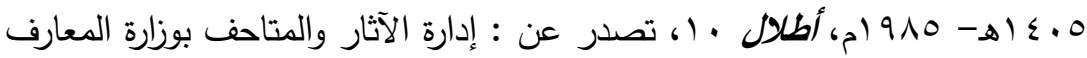

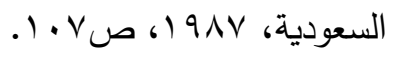

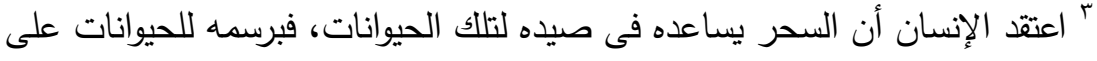

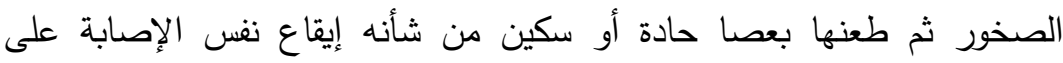
الحيوان الذي تم رسم صورته على الصخرة.

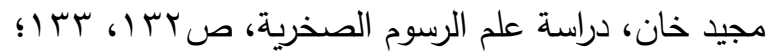

Bednarik. R. G and Khan. M., Scientific Studies of Saudi Arabian Rock Art, Rock Art Research 2005 - Volume 22, Number 1, p.72. 


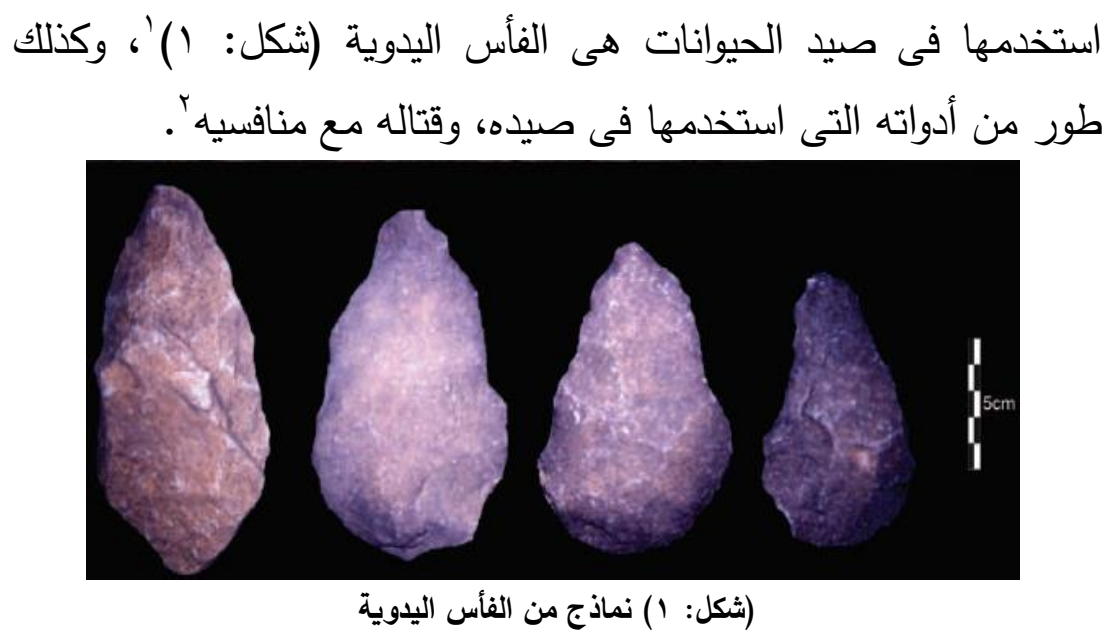

Groucutt. H. S and Petraglia. M. D., The Prehistory of the Arabian Peninsula: Deserts,Dispersals, and Demography, Evolutionary Anthropology 21(2012). f.3 مناظر أسلحة القوس

استخدم الإنسان القوس في عملية صيد الحيوانات"؛ فقى الثويمس؛

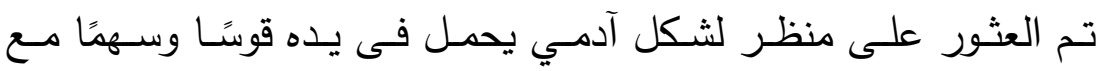

${ }^{1}$ Groucutt. H. S and Petraglia. M. D., The Prehistory of the Arabian Peninsula: Deserts,Dispersals, and Demography, Evolutionary Anthropology 21(2012), pp.116, 117.

${ }^{2}$ Majeed Khan, Recent Rock Art and Epigraphic Investigations in Saudi Arabia, Proceedings of the Seminar for Arabian Studies, Vol. 21, Proceedings of the Twenty Fourth SEMINAR FOR ARABIAN STUDIES held at Oxford on 24th - 26th July 1990 (1991), p.115.

${ }^{3}$ Howe. B., Two Groups of Rock Engravings from the Hijāa, Journal of Near Eastern Studies, Vol. 9, No. 1 (Jan., 1950), p.11.

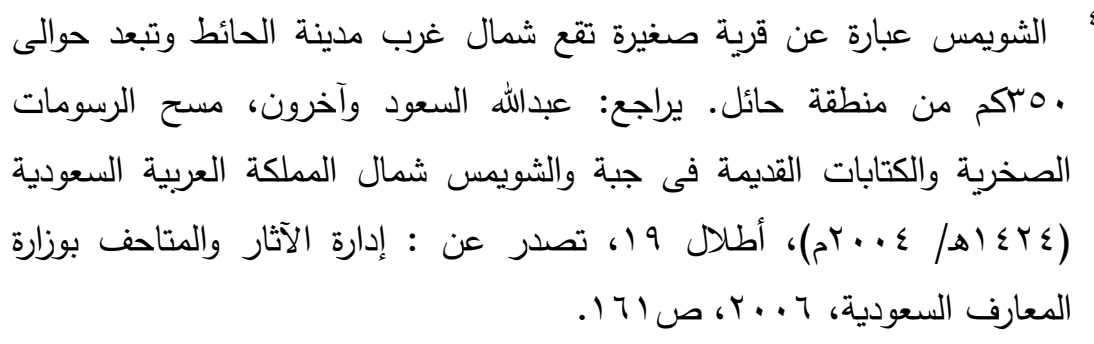




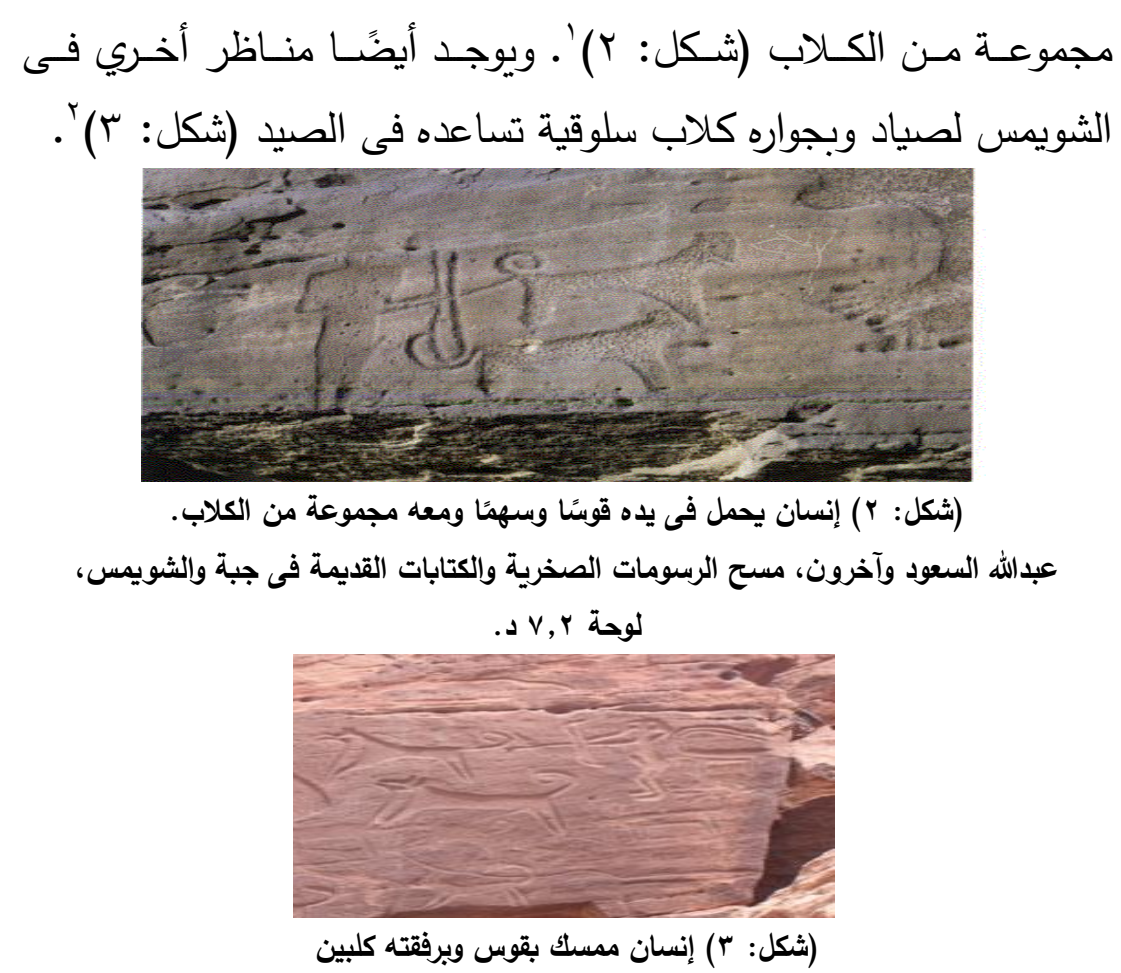

Jennings. $R$ and others., High-resolution geospatial surveying techniques provide new insights into rock-art landscapes at Shuwaymis, Saudi Arabia, Arab. arch. Epig 25 (2014), Fig.14

وبخصوص الكلب فهو من أوائل الحيوانات التى استأنسها الإنسان؛؛ وذلك لمساعدته فى مطاردة الحيوانات لصيدهاء

$$
\text { ' عبدالله السعود وآخرون، المرجع السابق، صسب ا. }
$$

2 Jennings. R and others., High-resolution geospatial surveying techniques provide new insights into rock-art landscapes at Shuwaymis, Saudi Arabia, Arab. arch. Epig 25 (2014), p.6.

$$
\begin{aligned}
& \text { ץ بحمة بنت عواد السناني، دراسة وصفية تحليلية لمجموعة من الرسوم الصخرية في منطقة } \\
& \text { المدينة المنورة، مجلة دراسات فى علم الآثار والتراث، مجلة محكمة تعنى بالآثار والتراث، }
\end{aligned}
$$

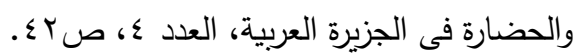

${ }^{4}$ Ryckmans. J., "An Ancient Stone Structure for the Capture of Ibex in Western Saudi Arabia", Proceedings of the Seminar for Arabian Studies, Vol. 6, Proceedings of the Ninth SEMINAR FOR ARABIAN STUDIES held at The School of Oriental \& African Studies and the Institute of Archaeology, London on 7th-9th July, 1975 (1976), p.164. 


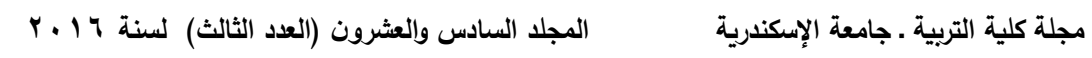

وعُثر فى الجبة'على رسوم صخرية لرجال ونساء يحملن أقواسًا تُستخدم للصيد (شكل: ع)' ؛

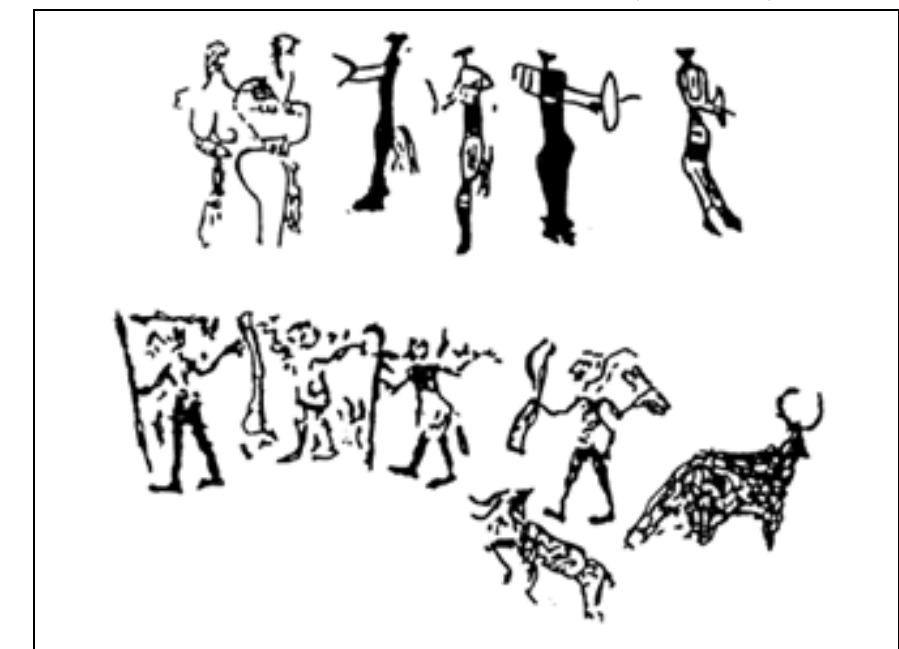

(ثكل: ؛ ) منظر لرجال يحملون أقواسًا للصيد (الجبة شمال المملكة العربية السعودية)

Majeed Khan, A Critical Review of Rock Art Studies in Saudi Arabia, p.433

'توجد الجبة بصحراء النفود فى شمال المملكة وتغطى مساحة .... . . بكمץ بين

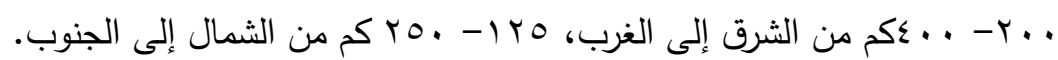

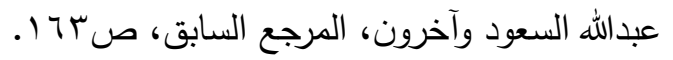
وكان فناني الجبه والشويم ذوي مهارات عالية؛ فكانت لديهم القدرة على تصوير حياتهم الاجتماعية والثقافية والدينية والاقتصادية بشكل فني متميز على عكس الرسوم الصخرية المنتشرة فى الأجزاء الأخرى من الجزيرة العربية إذ لم ترق إلى الى لهيله ذات المستوى المهاري والفنى.

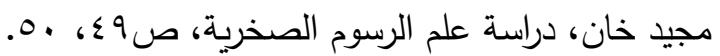

2 Majeed Khan, A Critical Review of Rock Art Studies in Saudi Arabia, p.433; Clarke. C., Rock Art at Jubba, Northern Saudi Arabia, Proceedings of the Seminar for Arabian Studies, Vol. 9, Proceedings of the Twelfth SEMINAR FOR ARABIAN STUDIES held at the School of Oriental \& African Studies and Institute of Archaeology, London on 10th - 12th July, 1978 (1979), p. 80. 
ويوجـد منظـر لرجـل يمســك فـى يـده قوسًــا يسـتخدمه فـى الصـيد

(شكل: م)

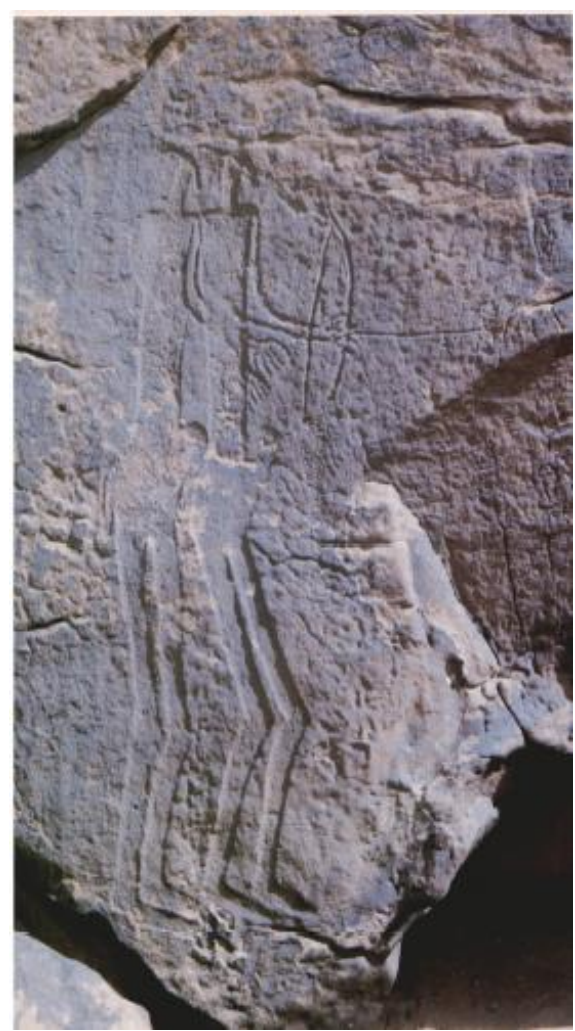

(شكل: ه ) رجل يمسك قوسًا فى يده

Zarins. J., Early Rock Art of Saudi Arabia, Archaeology, Vol. 35, No. 6 (November/December 1982), p.26.

وعثر على منظر آخر فى الجبـة لرجلين في حالـة قتال بالسـهام والأقواس (شكل: ج) وتم تأريخ اللوحة إلى فجر عصر التأريخُ .

${ }^{1}$ Zarins. J., Early Rock Art of Saudi Arabia, Archaeology, Vol. 35, No. 6 (November/December 1982), p.26.

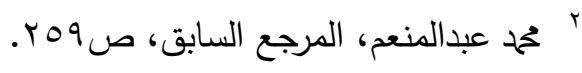




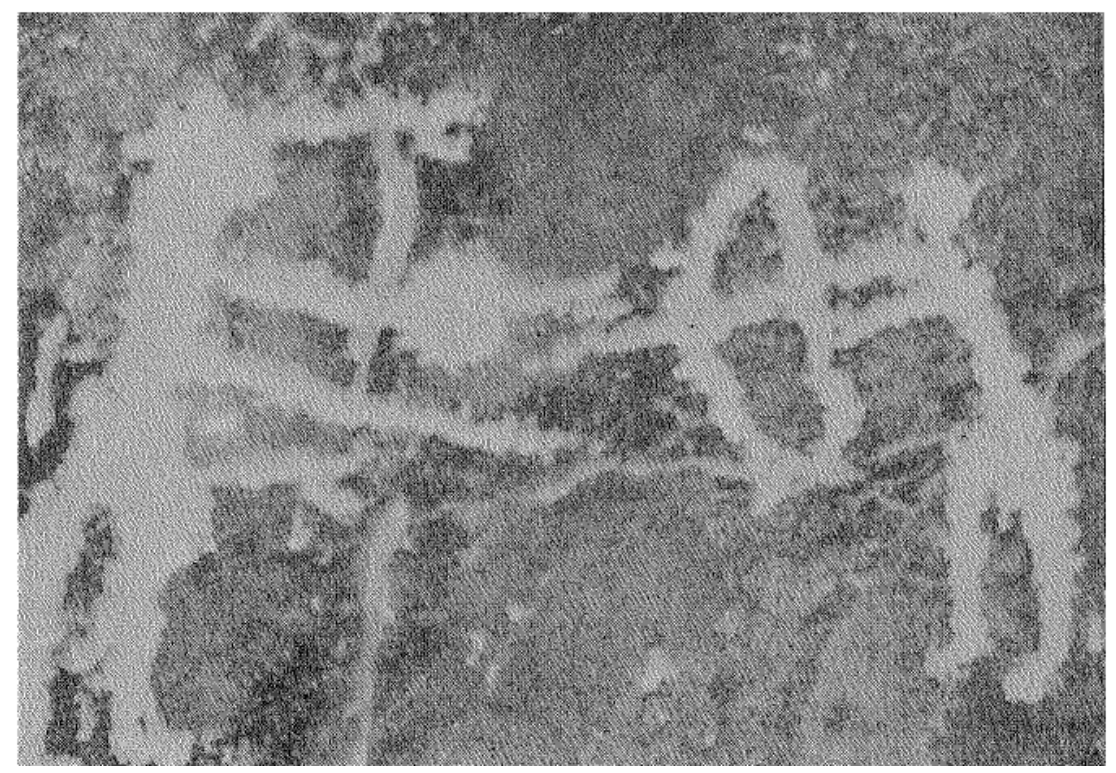

$$
\begin{aligned}
& \text { (شكل: 7 ) رجلان فى حالة حرب بالسهام } \\
& \text { محلم عبدالمنعم، المرجع السابق، شكل ؛ ؛ ؛ ؛ } 1
\end{aligned}
$$

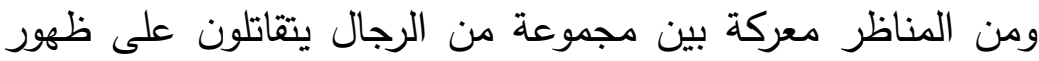

$$
\text { جيادهم (شكل: V)' }
$$

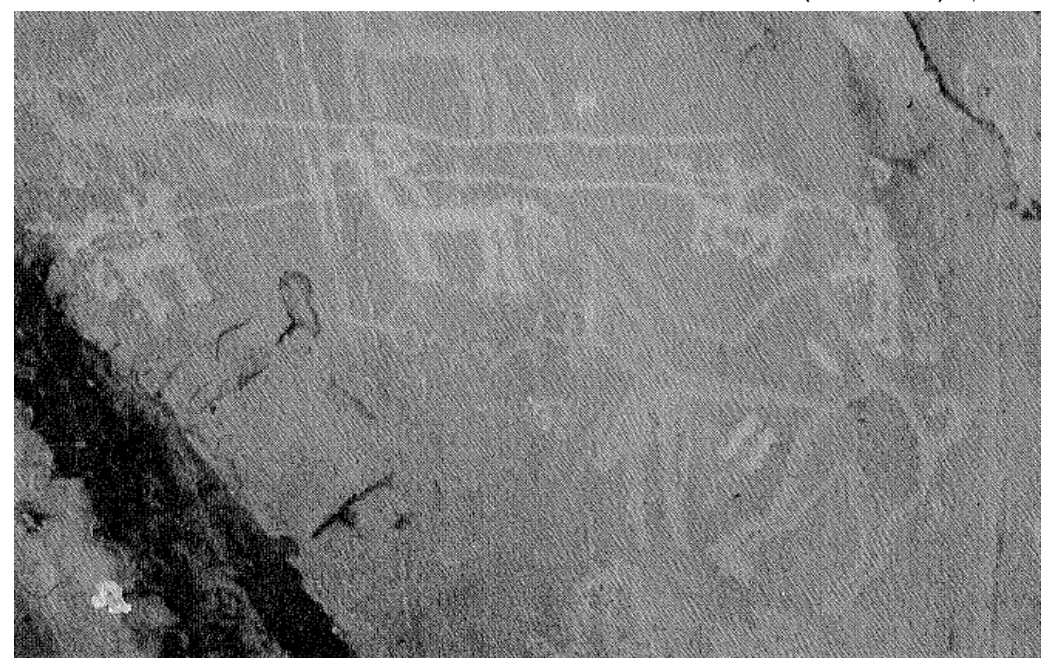

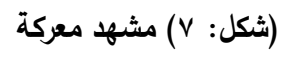

محمد عبدالمنعم، المرجع السابق، شكل ؛ : 10

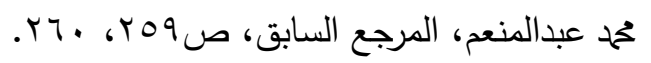


وفي محافظة تثليت' بمنطقة عسير عثر على منظر لمجموعة من

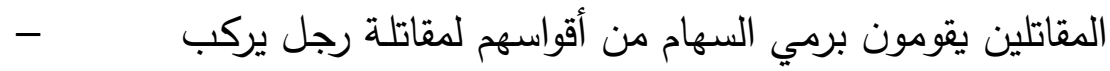

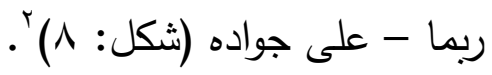

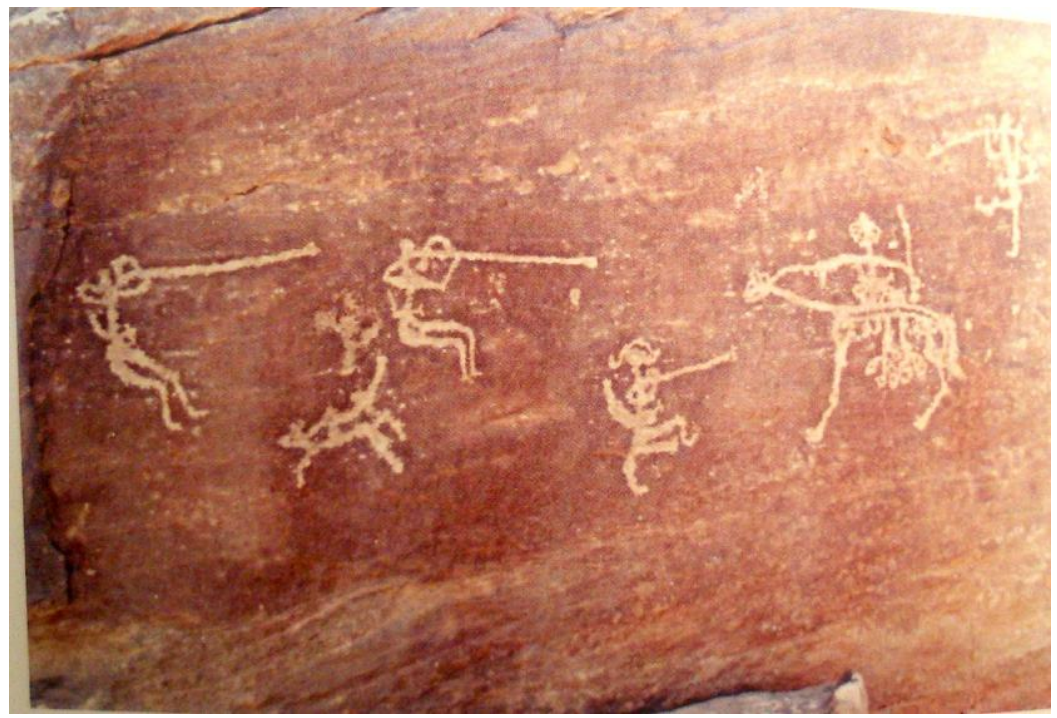

(شكل: ^) مسفر بن سعد بن تحم الخثعى، موسوعة الآثار والتراث والمعالم السياحية في منطقة عسير - دراسة توثيقية، الجزء الثامن، تثليت،

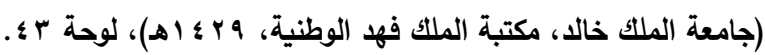

ويوجد مشهد للصيد يشتمل على أقواس، وكلاب وحيوانات أخرى.

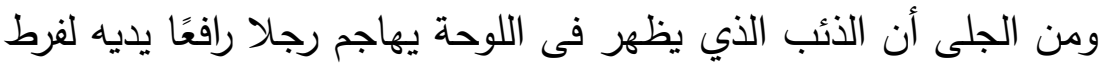

فزعه، بينما يُرى اثنان من زملائه يتهيآن لقتل الذئب بسهام تخرج من لنه

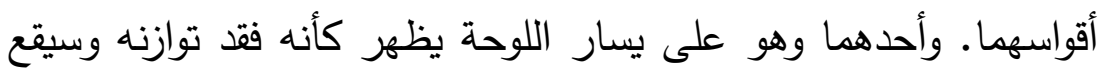

'يطلق اسم "تثليث" على الوادي المشهور بوادي تثليث بمنطقة عسير، ويعد واحدًا

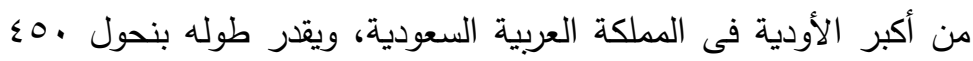

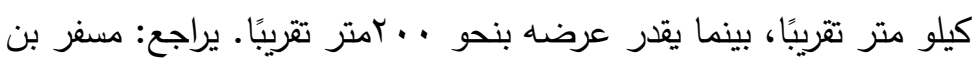
سعد بن محمد الخثعمى، موسوعة الآثار والتراث والمعالم السياحية في منطقة

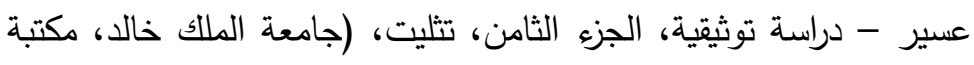

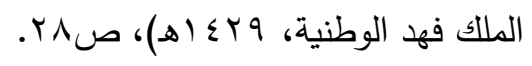


على ظهره بينما ترتفع رجله اليمنى إلى أعلى فى الهواء، وتضم اللوحة

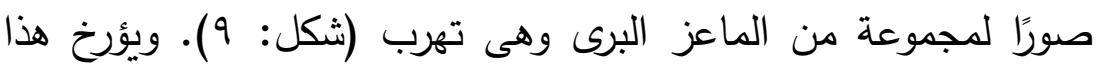
المنظر لفجر عصر الكتابة. ومن المتوقع أن لهذا المنظر فترتين زمنيتين

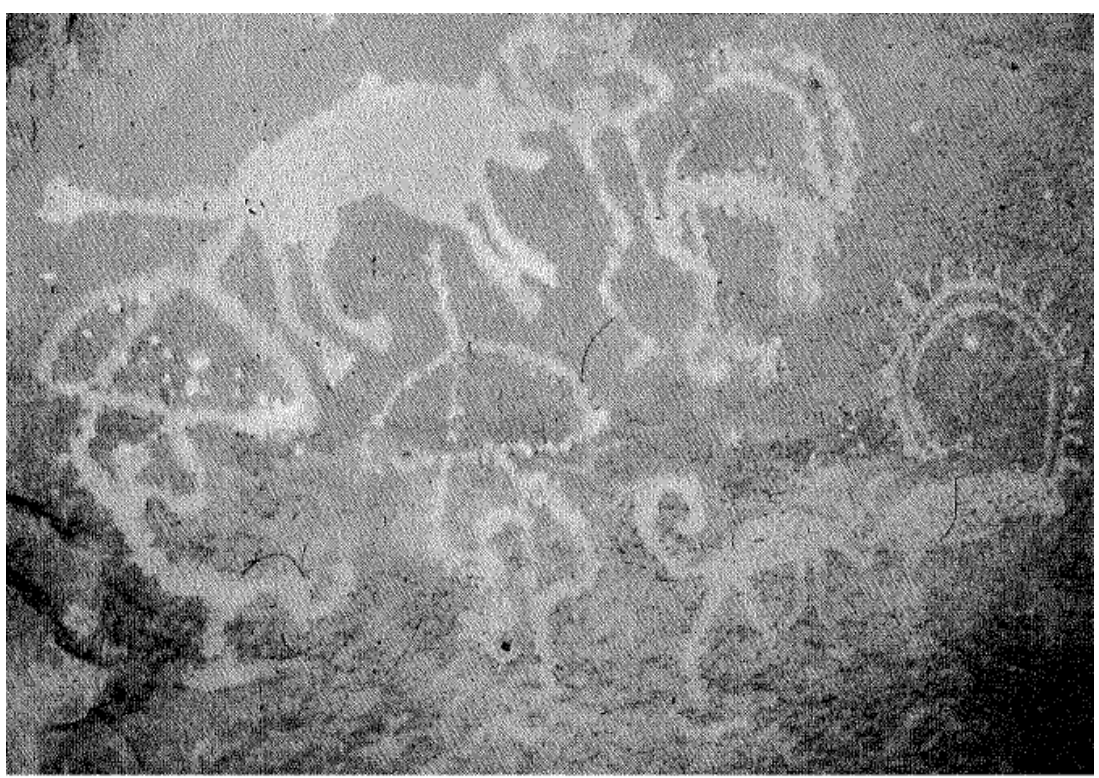

$$
\text { (شكل: 9 9) مشهـ قنص مع مجموعة من النبال }
$$

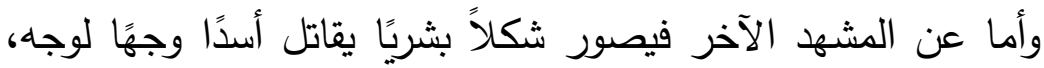

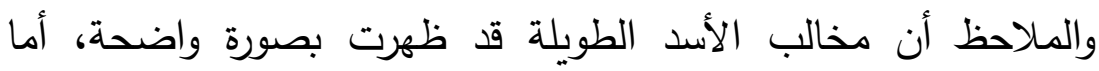
الأرجل الأمامية للأسد فتُرى مرفوعة بصورة طفيفة بينما تستند أرجله

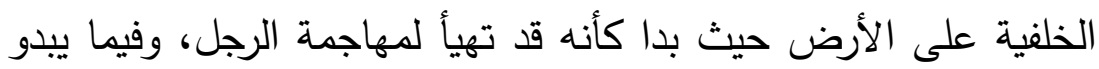
أن الرجل قد استبق الأسد حيث غرس سهمًا فى بدنه بينما كانت يده

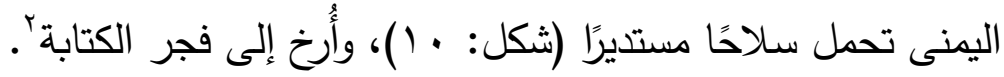




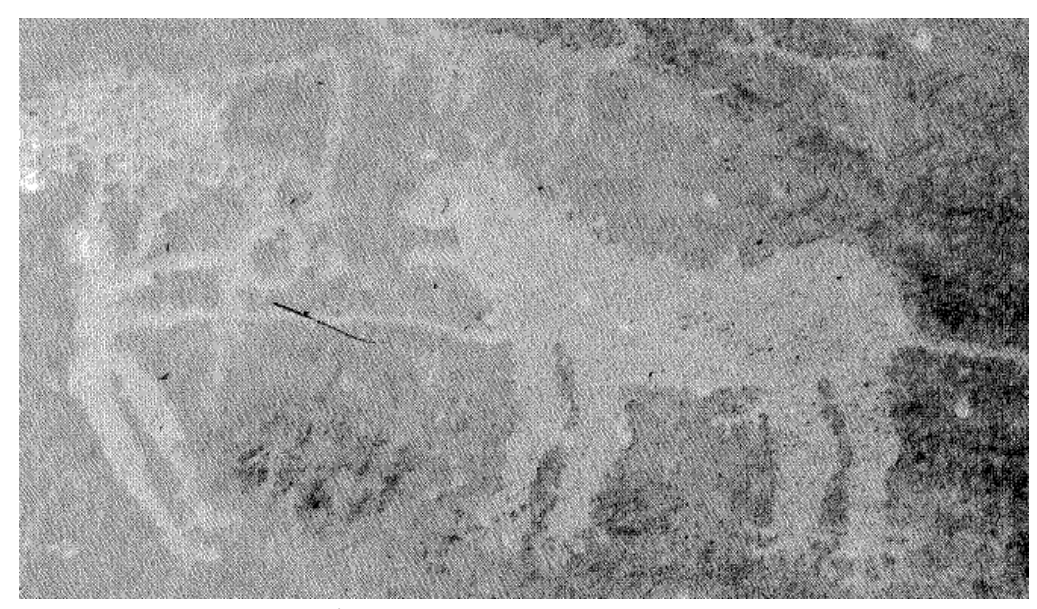

(شكل: · م 1) منظر لرجل فى مواجهة أسد

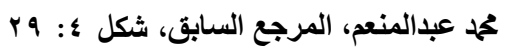

ومسن عـرض منـاظر اسـتخدام القـوس كسـلاح للإنسـان، يتضـح أنـه

استخدمه فى صسيد حيواناته، وأيضًا استخدمه فى صـراعه البشري بين

الأفراد بعضهم ببعضًا. وقاتل به الحيوانات المفترسة مثل الأسد والذئب. الرمع أو الحربة

وعثر فى موقع بير هيما (Bir Hima) بجنوب غرب المملكة العربية

السـودية، على منظـر لشـكل بشـري يمسـك بيده رمحًا بيده اليسـرى، ويمسك بيده اليمنى درعًا (شكل: . )' .

${ }^{1}$ Zarins. J., Early Rock Art of Saudi Arabia, p. 21. 


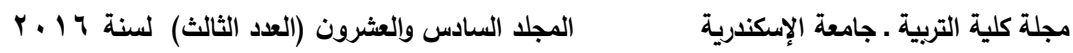

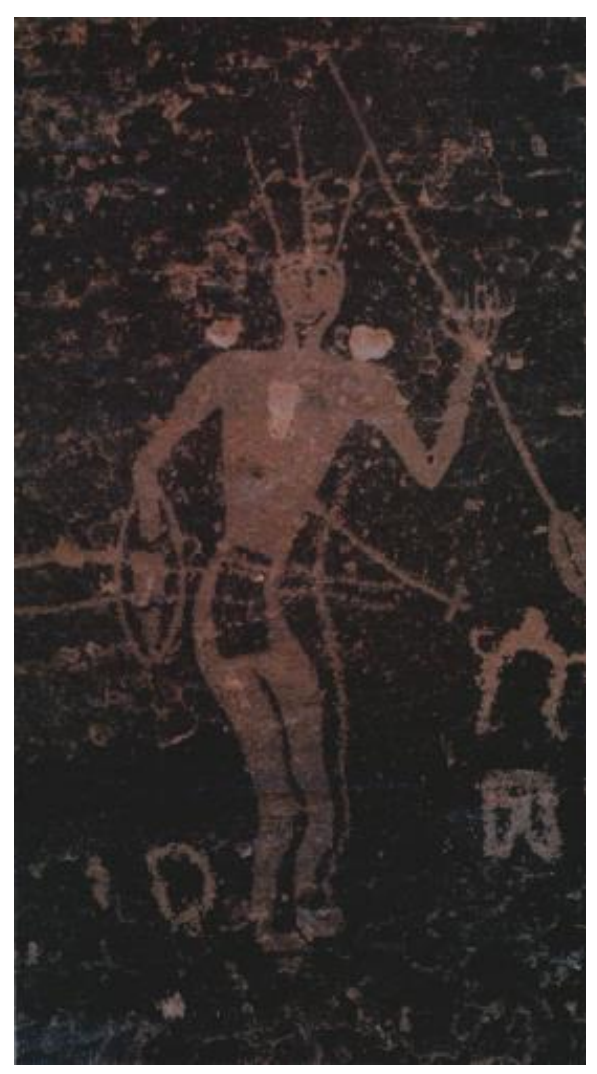

(ثكل: ) منظر لرجل يمسك رمح بيده اليسرى ودره باليد اليمنى

Zarins. J., Early Rock Art of Saudi Arabia, p.21.

ويوجد منظر بالقرب من المدينة لمجموعة من الرجال يمسك أحدهم

رمحًا بيده اليمنى (شكل: (1))، وعلق كورتيناى تومبسون -Courtenay)

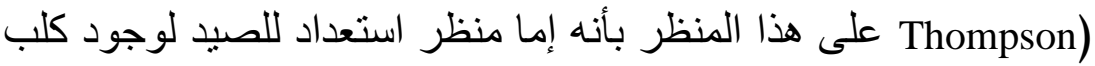
فى المنظر، أو أنه رقصة طقسية'.

1 Thompson. C., Rock Engravings Near Madinah, Saudi Arabia, Proceedings of the Seminar for Arabian Studies, Vol. 5, Proceedings of the Eighth SEMINAR FOR ARABIAN STUDIES held at The Oriental Institute, Oxford on 3rd5th July, 1974 (1975), p.27. 


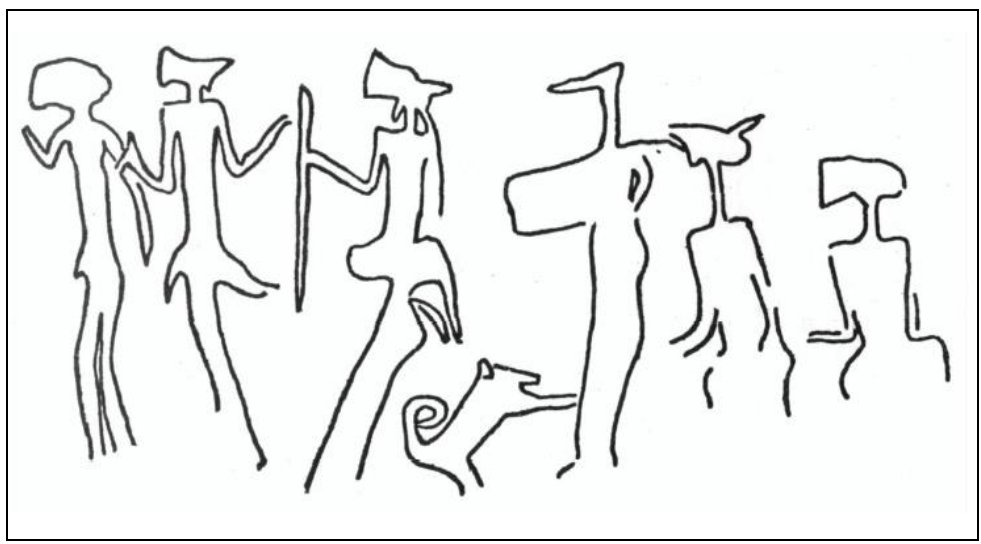

(شكل: 11) منظر ربما يعبر عن استعداد للصيد أو أنه منظر طقسي

Thompson. C., Rock Engravings Near Madinah, Saudi Arabia, fig.9.

وأيضًّـا فـى الجبـة تـم العثـور على أشـكال بشـريـة تحمـل رواحًا

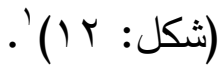

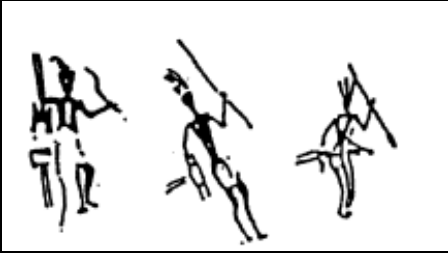

(شكل: با 1 ) منظر لرجال يحملون رماح (الجبة شمال المملكة العربية السعودية)

Majeed Khan, A Critical Review of Rock Art Studies in Saudi Arabia, p.433.

ومنظر أخر بجبل قارا بنجران لرجل يركب حصانه ويمكك رمحًا

(شكل: (1)

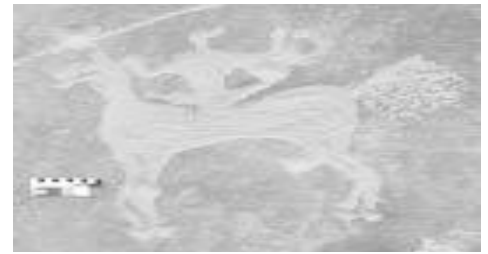

(شكل: \& 1 ) رجل يركب حصان ويمكك رمح بجبل قارا بنجران

Bednarik. R. G and Khan. M., Scientific

Studies of Saudi Arabian Rock Art, fig.38.

${ }^{1}$ Majeed Khan, A Critical Review of Rock Art Studies in Saudi Arabia, p.433.

${ }^{2}$ Bednarik. R. G and Khan. M., Scientific Studies of Saudi Arabian Rock Art, p.72. 
ويوجد بجبل القصب - على طريق جدة الطائف على بعد حوالي كيلو مترا جنوب شرق جدة - منظر لحيوانات وشكل آدمي يمسك درعًا وعصا أو رمحًا (شكل: مان (1)، ويعلق نورمان م. والين وآخرون إن وجود

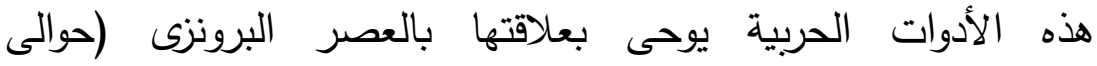

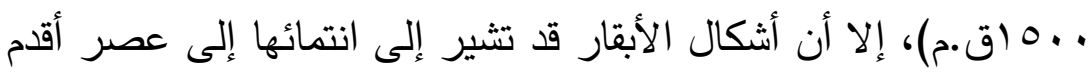

من ذلك بكثير'

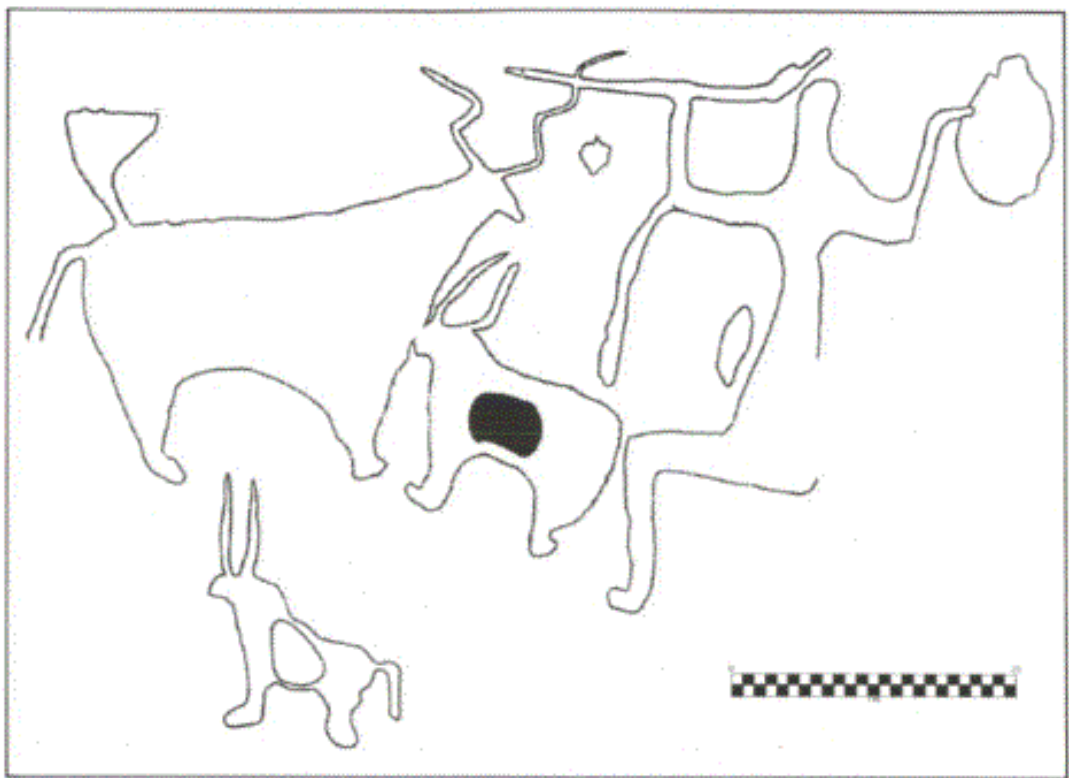

(شكل: 0 (1) رجل يمسك درعًا وبالأخرى عصا أو رمح وأمامه أبقار

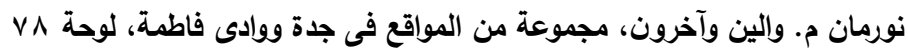

نورمان م. والين وآخرون، مجموعة من المواقع فى جدة ووادى فاطمة، أطلال 1)، تصدر عن :

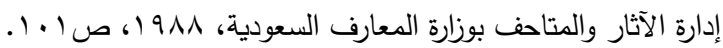


ويوجد منظر في العلا' قرب مدائن صالح لرجل - ربما - يركب

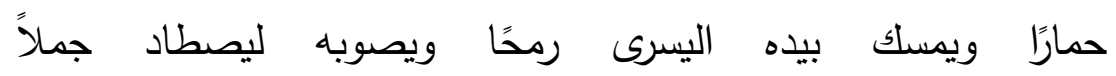

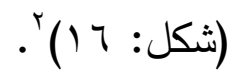

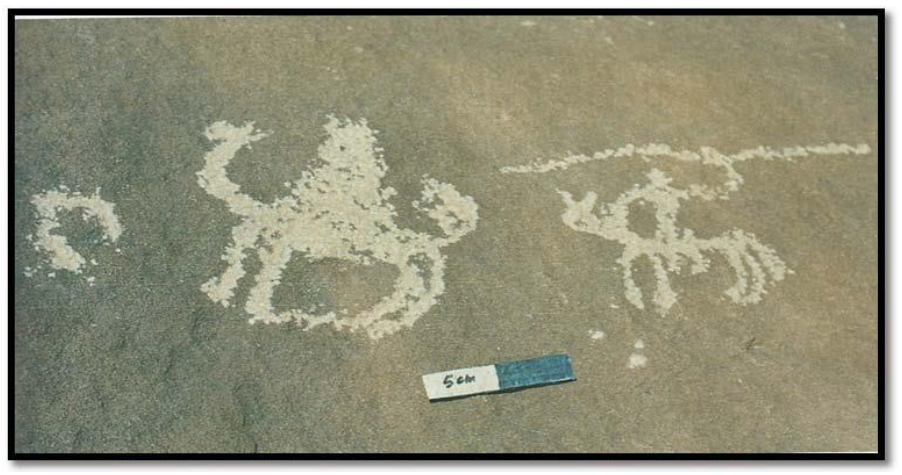

(شكل: 14) العلا - قرب مدائن صالح منظر رجل يركب حمارًا ويمكك بيده اليسرى رمحًا يصطاد بها جملاً

مجيد خان، التركيب والشكل فى الرسوم الصخرية فى شمال المملكة العربية السعودية، أطلال 11،

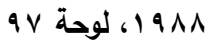

وفي وادى المياهّ، منظر لصيد جمل، يظهر الفارس ممسكًا برمح

'العُلا: هى موضع بناحية وادى القري بالمدينة المنورة.

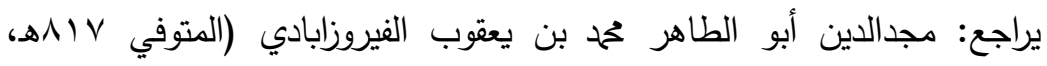

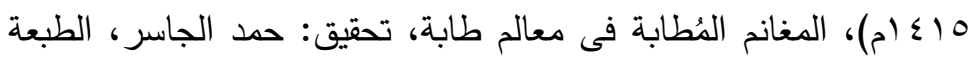

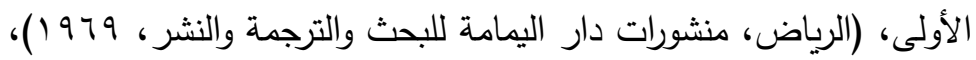

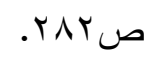

' رحمة بنت عواد السناني، دراسة وصفية تحليلية لمجموعة من الرسوم الصخرية

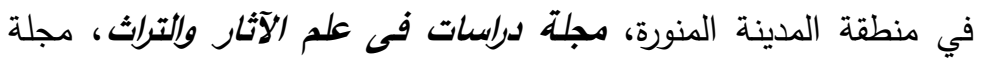

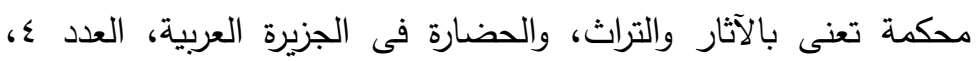

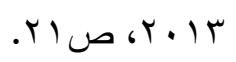

r بقع وادي المياه جغرافيا بين السهل الساحلي على الخليج العربي وهضبة الصمان غربًا.

يراجع: نبيل يوسف الثيخ يعقوب، الرسومات الصخرية في المنطقة

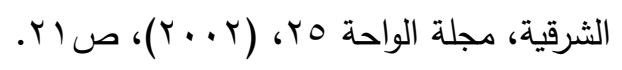


وممسكا بيده الأخري بالفرس من شعر الرقبة: الساقين متدليين للأسفل

$$
\text { وهو متوجه للجمل (شكل: IV)' }
$$

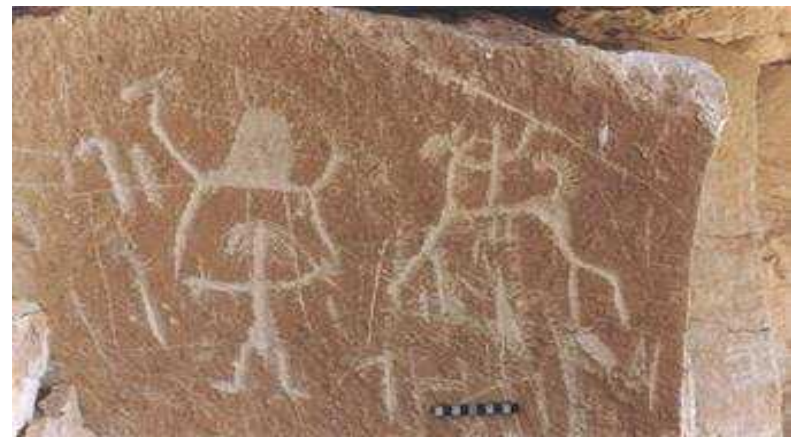

(شكل: V V إدى المياه، منظر لرجل يصطاد جملاً

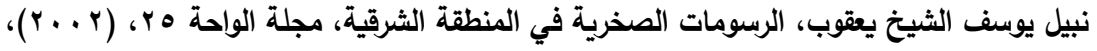
شكل ؛.

وفى نجران فى جنـوب المملكة العربية السـودية منظر أخر لرجل

يصطاد جملاً وهو راكب على فرسـه وبيده اليمني حربه، بينما زميل لله

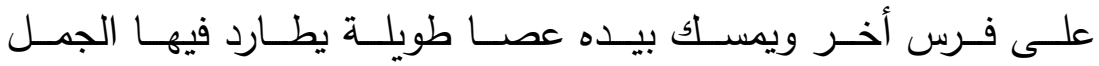
(شكل: (1)

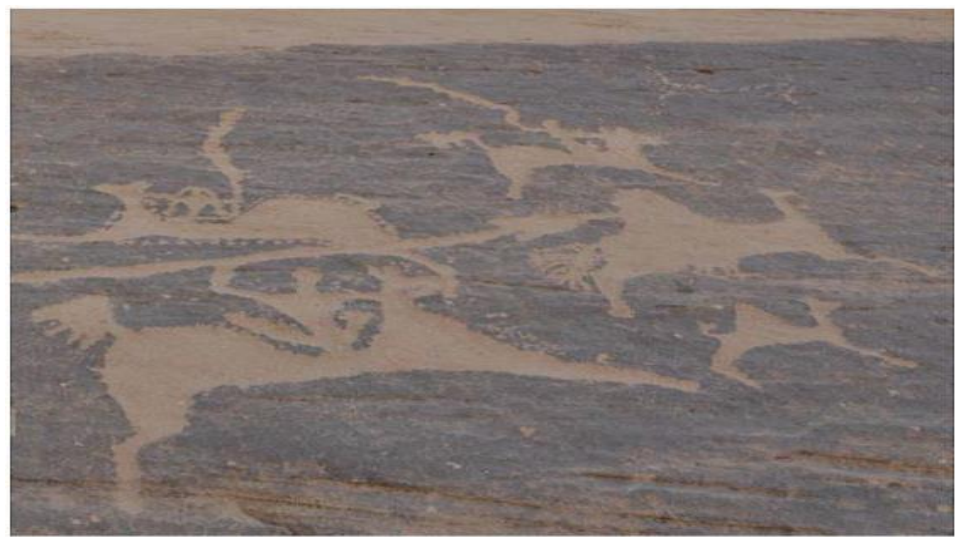

(شكل: 1) (13) نجران، رجل يقوم بصيد جمل وزميل له يساعده فى مطارد ذلك الجمل Majeed Khan, Rock Art of Saudi Arabia, Arts 2, (2013), Fig.9

'نبيل يوسف الشيخ يعقوب، الرسومات الصخرية في المنطقة الثرقية، مجلة الواحة (ro

${ }^{2}$ Majeed Khan, Rock Art of Saudi Arabia, Arts 2, (2013), p.454. 


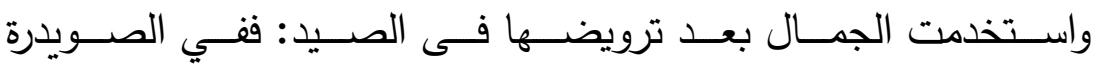
(تقع على بعد ستين كيلو مترًا إلى الثرق من المدينة) منظر لصيادين

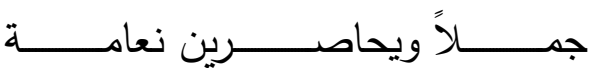
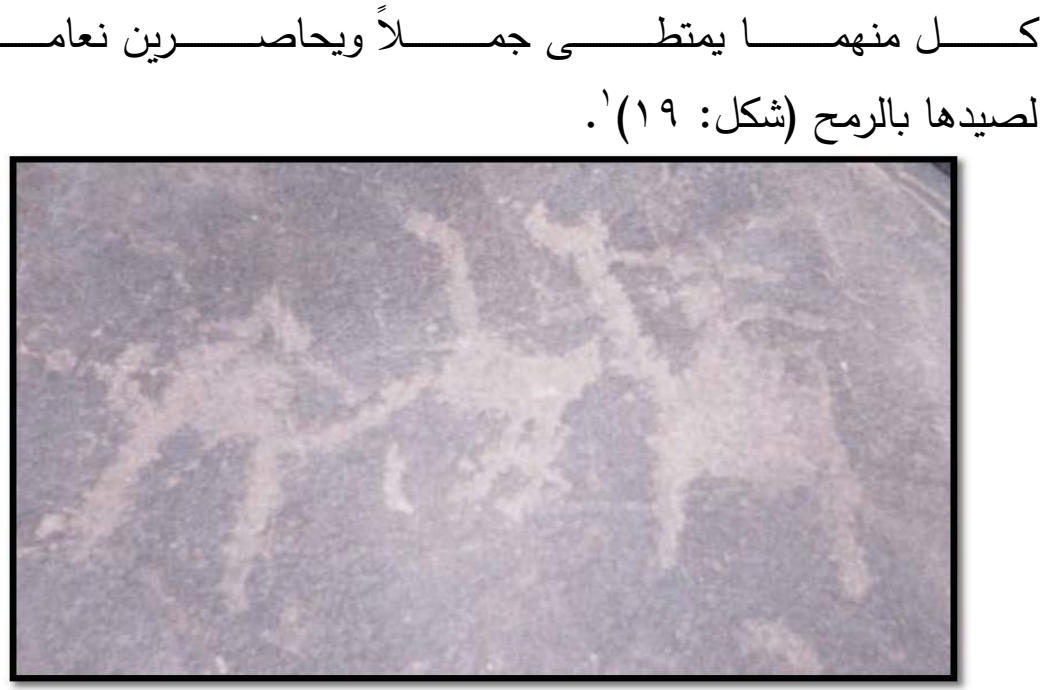

(شكل: 9 1 ) صيادان يمتطى كل واحد منهما جمل لصيد نعامة

صالح بن محم المطيرى، تقرير عن وادي الصويدرة بمنطقة المدينة المنورة

http://www.altorthalatiq.com/vb/showthread.php?t=1428\&highlight

ويتضح مما سبق أن الجمل الذي يمتطيه الصياد، لا يظهر فى

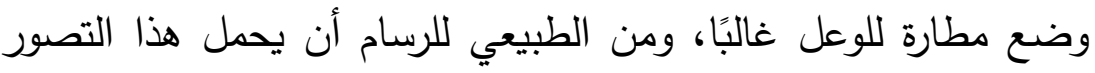

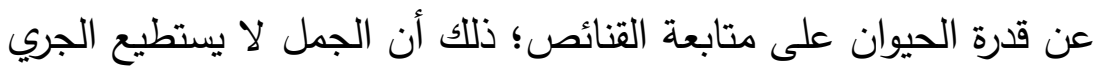

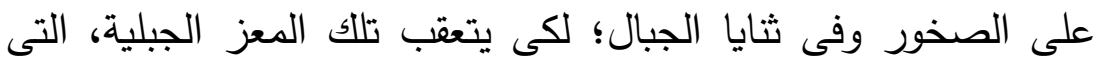

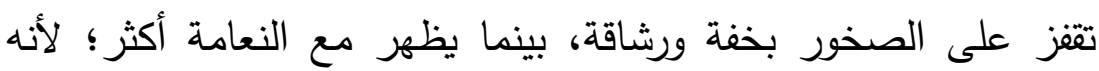

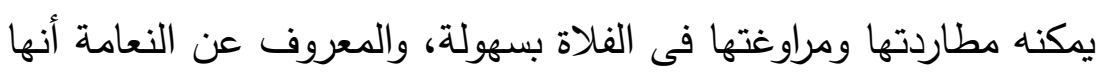

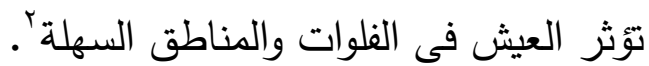

صالح بن ححم المطيرى، تقرير عن وادي الصويدرة بمنطقة المدينة المنورة http://www.altorthalatiq.com/vb/showthread.php?t=1428\&highli ght 
وتذهب رحمة السناني إلى كثرة تصوير الجمال يستدل منها على قوة العلاقة التى ربطت بين الجمل والإنسان بدءًا من المحاولات الأولى؛ لاستتئناسه بتقييده، وحتى الاعتماد عليه في عمليات الصيد والحروب والمطاردة، ووصولاً للألفة الثديدة بين الجمل وصاحبه؛ حيث يصور وهو يطعده بيده ويلاطفه' وفى موقع الفية بأبها بمنطقة عسيرَ' عُر على نقش لفارسين كل منهما يمتطي حصانه ويمسك كل فارس حربه ويصوبها ضد الأخر فى

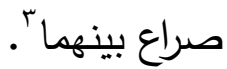

رحمة بنت عواد السناني، دراسة وصفية تحليلية لمجموعة من الرسوم الصخرية في منطقة المدينة المنورة، صبكء

r تقع منطقة عسير فى الجزء الجنوبي الغربي من المملكة العربية السعودية، وتمتد

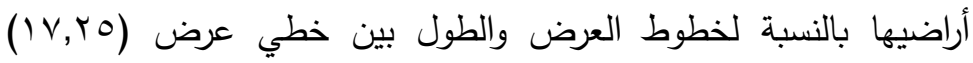

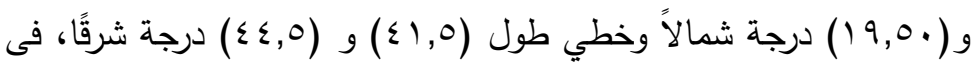
حين تبلغ مساحتها الإجمالية نحو (•^) ألف كيلو متر مربع وهي تعادل (r,V)

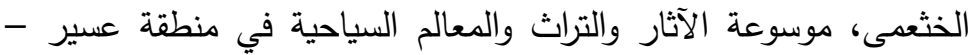
دراسة توثيقية، الجزء الأول، أبها والمراكز التابعة لها، (جامعة الملك خالد،

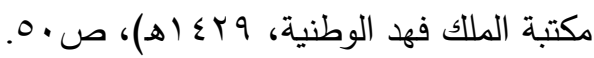




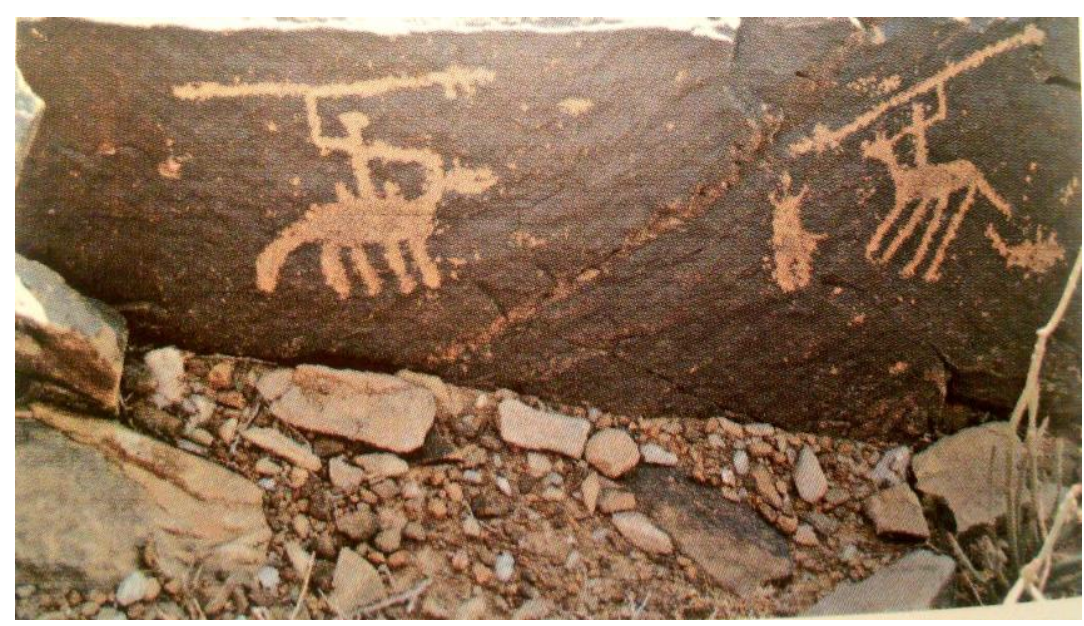

$$
\text { (شكل: ) فارسان فى حالة حرب بالرماح }
$$

مسفر بن سعد بن محمد الخثعمى، موسوعة الآثار والتراث والمعالم السياحية في منطقة جامعة) عسير - دراسة توثيقية، الجزء الأول، أبها والمراكز التابعة لها، بوسها،

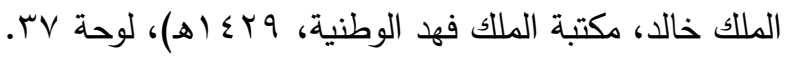
ومن الجدير بالذكر أن كل المناظر المرتبطة بالحربة أو الرمح كسلاح أستخدمت فى صيد الحيوانات مثل النعام والجمال كمصدر لغذاء الإنسان. واستخدمها أيضًا فى صراعه البشري.

\section{العصا المعقوفة}

عُثر فى جبل عرفاء الذي يقع على بعد هاكم شمال شرق الطائف على شكل لرجالٍ أقل من · عسم فى الارتفاع، لهم أذرع وسيقان مبالغ فى طولها ولهم ذيول، ولعل الجدير بالماحظة أن هؤلاء القوم تعلوا رؤوسهم أغطية للرأس عليها ريش، وأنهم يحملون أقواسًا مزدوجة وسهامًا ذات رؤوس مستعرضة، وأنواعًا أخرى من العتاد، وأشخاصًا يرتدون ما 
يشبه القصكان ويقذفون عصيا وقضبانًا (شكل: .ب)'. ويؤرخ هذا المنظر إلى ما قبل الألف الثاني قبل الميلاد.

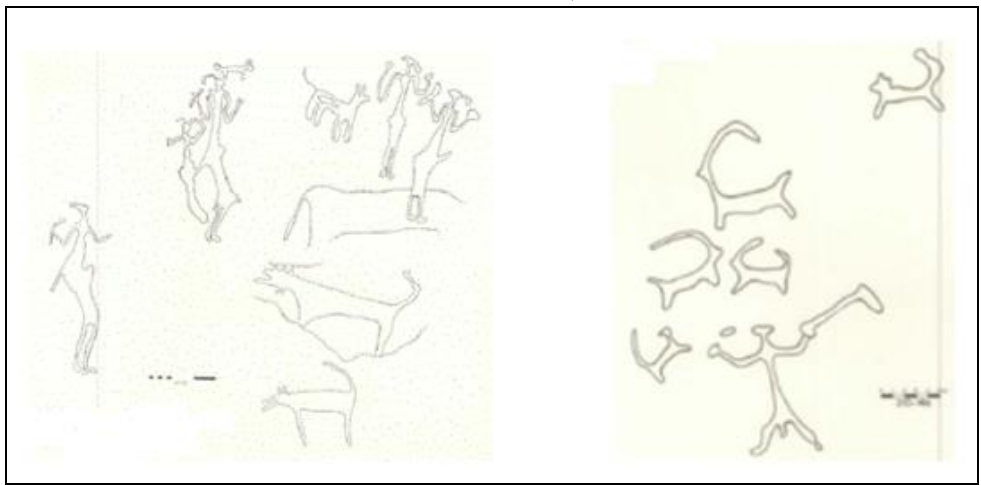

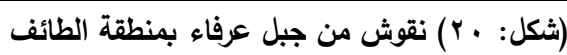

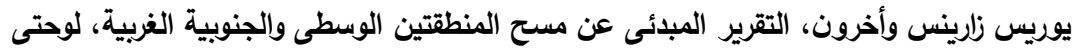

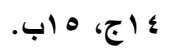

وقد تم العثور على مناظر فى موقع الحفنة شمال مهد الذهب شبيه

بمناظر جبل عرفاء - السابق ذكره - فقد عُر على منظر لغزلان وأشخاص بشرية تحملى العصى، وهؤلاء الأشخاص لهم أذرع طويلة وذيول ممتدة، وكذلك الهراوة التى تشبه "عصا الجولف" (شكل: (Y)'، وهى العصا المعقوفة.

يوريس زارينس وأخرون، التقرير المبئى عن مسح المنطقتين الوسطى والجنوبية

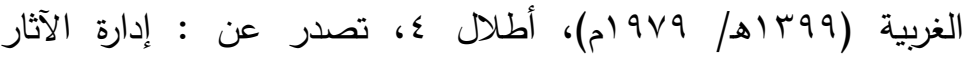

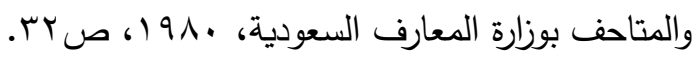




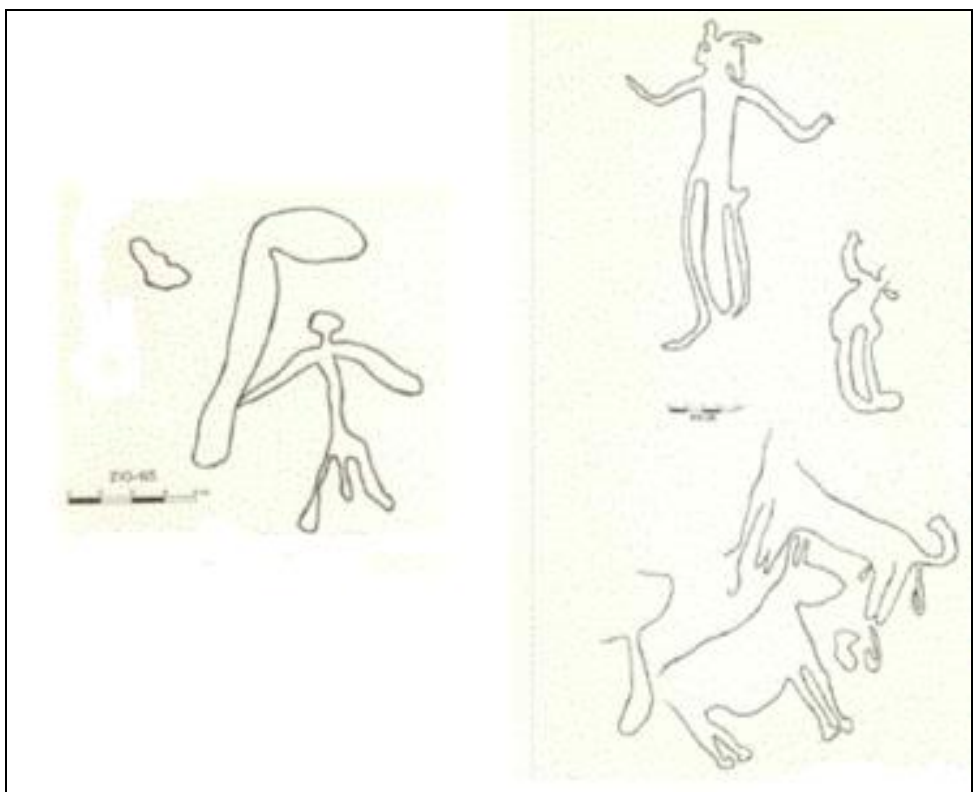

(شكل: (Y) نقوش صخرية من منطقة مناجم مهذ الذهب

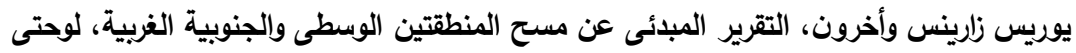

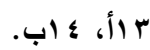

ربما تُعرف تلك الأداة باسم البوميرانج (Boomerang) أو المرتدة،

وهى التى يستخدمها الإنسـان فى الصسيد وذلك برميها حيث تدور تلك العصا إلى الإمام؛ لتؤدى غرضها بإصـابة الهدف ثم تعود إلى الرامسى' · وهي تستخدم لصيد الطيور ·

وفى منطقة بئر حما فى المنطقة الجنوبية الغربية منظر لرجل يمسك ما يعرف باللهراوة بيده اليمنى، وفي يده اليسرى قوس، ويلبس فــى وســـهله مـــا يعــرف بــالجراب الموضـــوع فيـــه خنجـــر • (شكل: r r (

${ }^{1}$ Adam. L., Primitive Art, London, 1963, p.88.

צو يوريس زارينس وآخران، برنامج المسح الأثرى الثامل لأراضى المملكة العربية السعودية. أ-التقرير

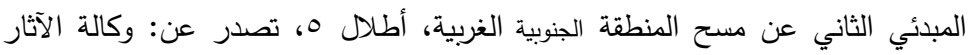

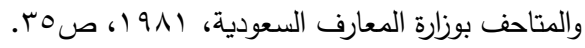




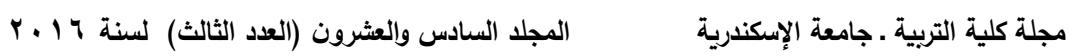

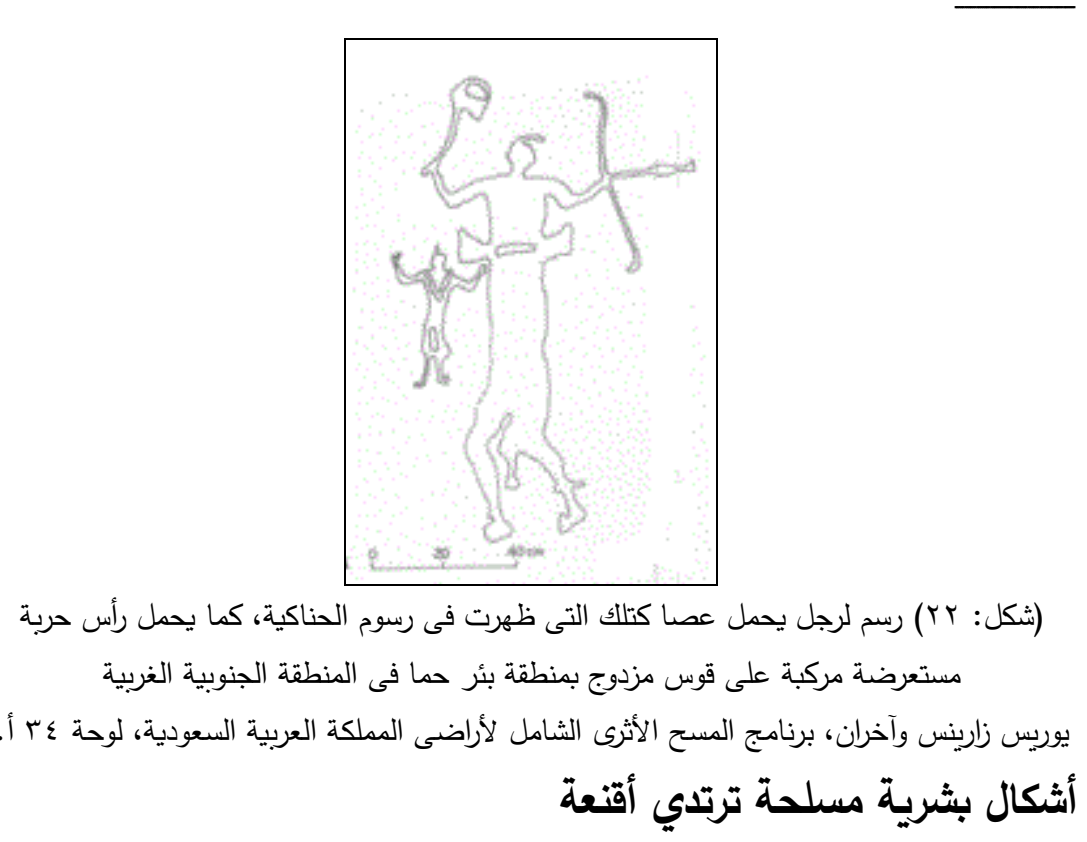

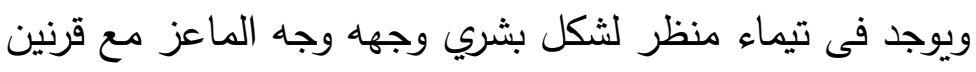

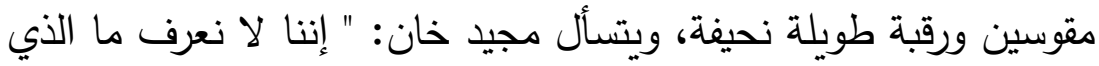
يريد الفنان تصويره أهو شكل إنسان بوجه ماعز، أم إنسانًا يرتدى قناعًا،

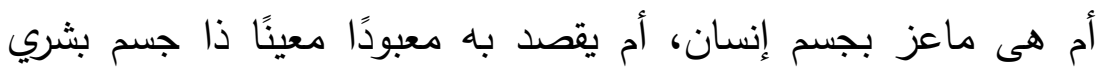
ووجه عنزة؟"' . ويستمر خان فى وصفه لهذا الثكل بأن الساقين منحيتان قليلاً، والذراعين النصف عرفوعتان وهما تمكسان بالقوس والسهام، والذيل متطاير نحو الخلف كالثراريب، وقد تم رسمه بالاقتران مع ثور • يظهر وهن

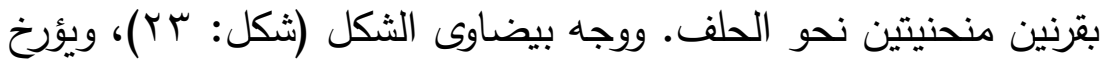
هذا الشكل بالعصر الحجري الحديث`.

مجيد خان، التركيب والثكل فى الرسوم الصخرية فى شمال المملكة العربية

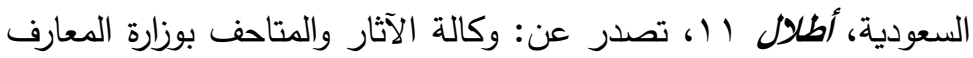

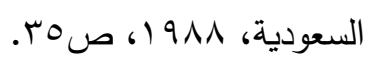

مجيد خان، التركيب والثكل فى الرسوم الصخرية فى شمال المملكة العربية

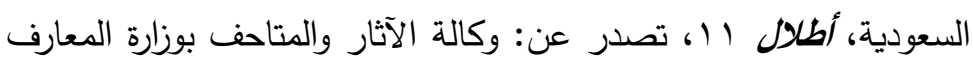

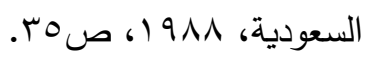




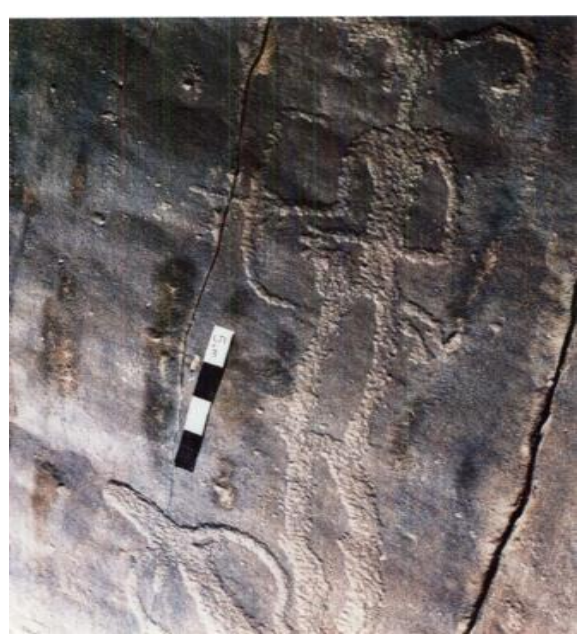

(شكل: r r شكل آدمى فى جنوب غرب تيماء بوجه يشبه الماعز

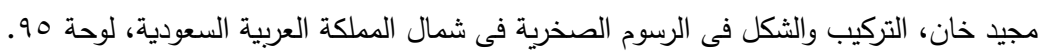
وعثر على الأشكال الآدمية ذات الوجوه الحيوانية بالقرب من لن المدينة المنورة، وهى تتثابه بتلك الموجودة بجُبة من ناحية الثكل وتكوين الجسد والأذرع العصوية التى تحمل القوس والسهم، ولكنها تختلف عن تلك الموجودة فى جبة بما لها من أرجل مستقيمة بالمقارنة بانحناءة الأرجل الموجودة فى أشكال جبة وكذلك فى وجه الماعز التى تظهر به (شكل: ع 'ب)'

' مجيد خان دراسة تحليلية للطقوس الدينية القديمة فى المنطقة الثالمية من خلال الرسوم الصخرية، أطلال با (، تصدر عن: وكالة الآثار والمتاحف بوزارة

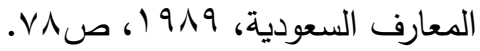

$$
\begin{aligned}
& \text { IVA }
\end{aligned}
$$




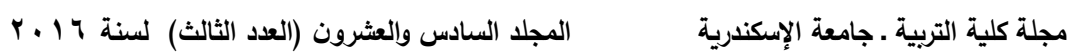

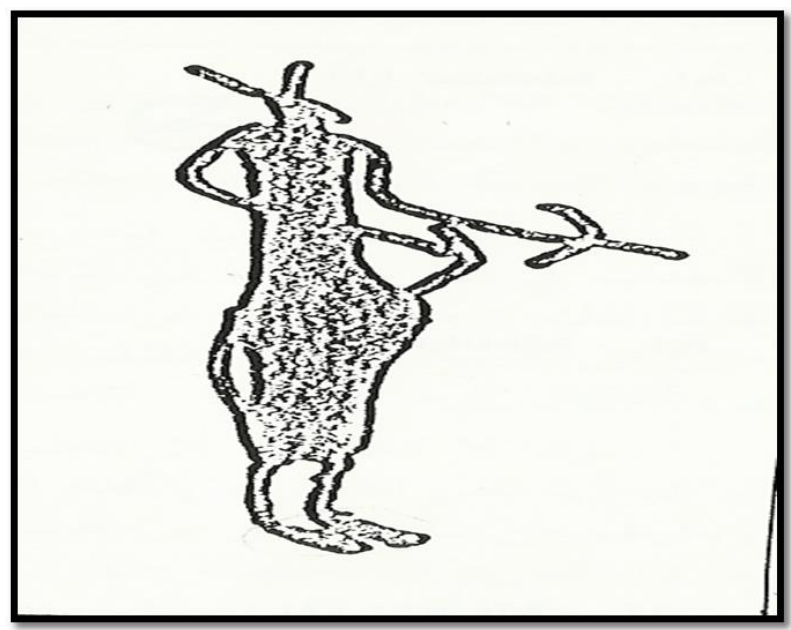

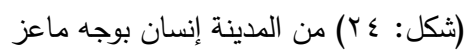

مجيد خان دراسة تحليلية للطقوس الدينية القديمة فى المنطقة الشمالية من خلال الرسوم الصخرية،

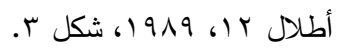

ويوجد في الجُبة شكل بشري برأس طائر ، ويمسك فى يده أداة

$$
\text { غير معروفة (شكل: مبr)' . }
$$

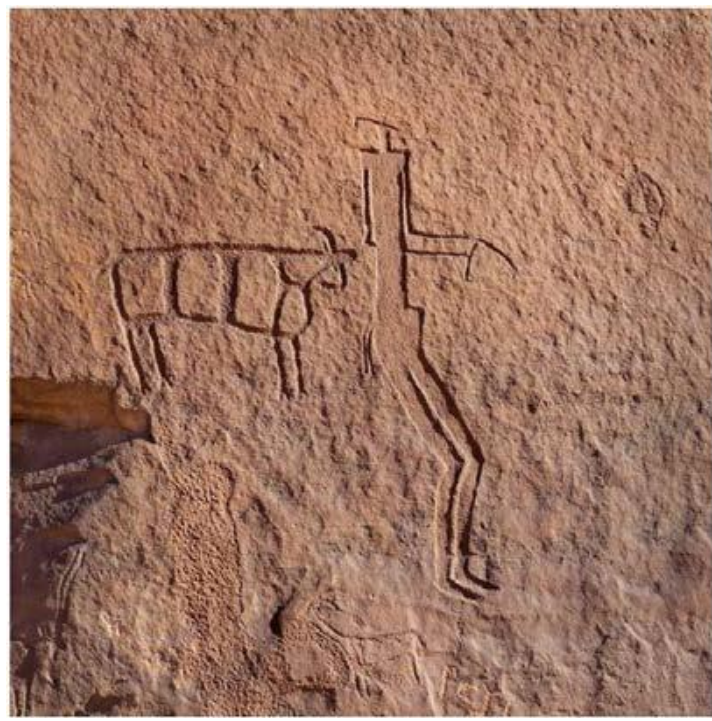

(شكل: ب 0) إنسان بوجه طائر ، يمسك فى يده أداة

Majeed Khan, Rock Art of Saudi Arabia, Arts 2, (2013), fig.1.

${ }^{1}$ Majeed Khan, Rock Art of Saudi Arabia, Arts 2, (2013), p.448. 
وترجح رحمة السناني أن هذه المناظر ربما ترمز لمعبوداتهم استتادا

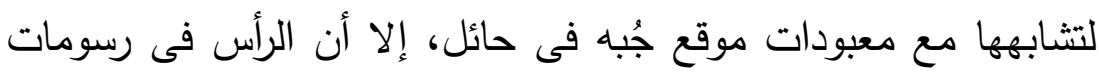

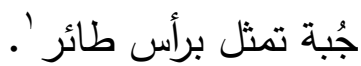
وتعقيبًا على ما سبق يمكن تفسير الثكل بأنه إنسان ارتدى قناعًا

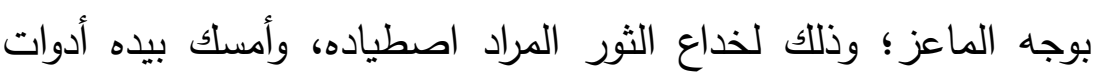
الصيد المتمثلة فى القوس والسهام، وحتى يَخدع الحيوان أكثر فلبس ما ودأ يشبه الذيل.

وفى موقع الجبة شكل بشري ضخم كأنه يلبس تاجًا ويطلق عليه لقب

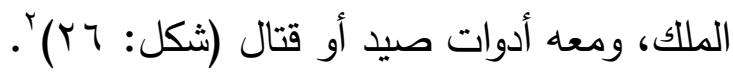

رحمة بنت عواد السناني، دراسة وصفية تحليلية لمجموعة من الرسوم الصخرية

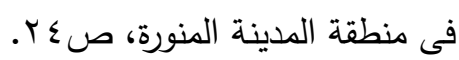

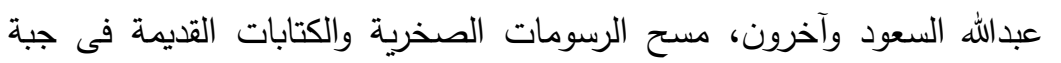

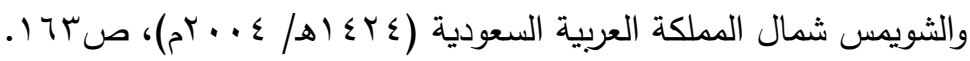




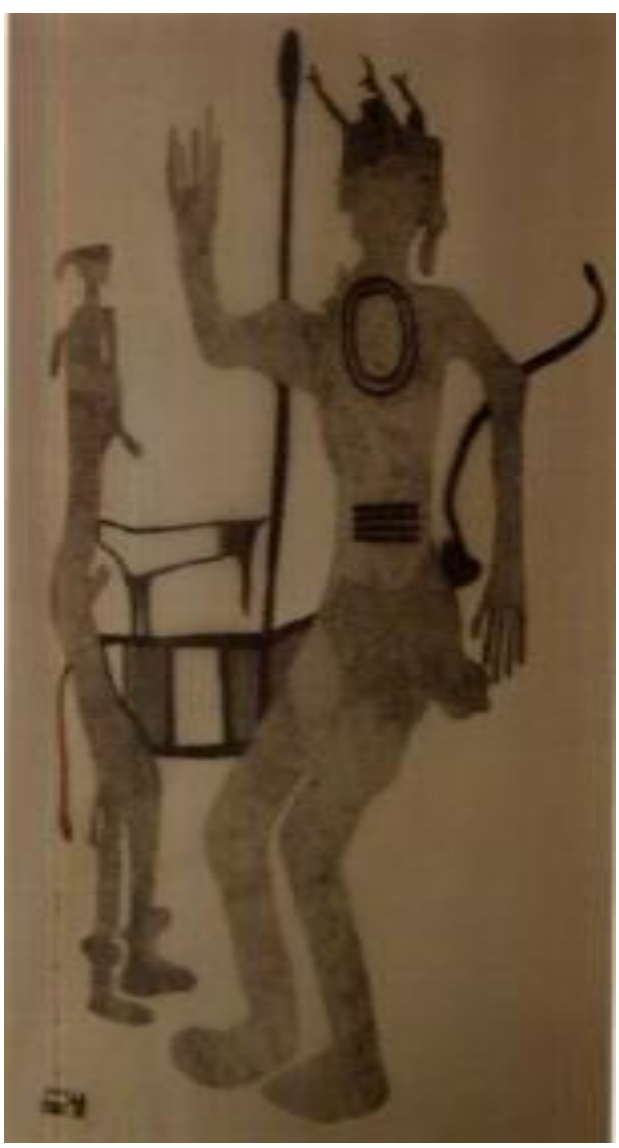

$$
\text { (شكل: ب r) ملك الجُبة }
$$

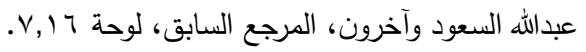

\section{مناظر ذات مدلول ديني مرتبطة بأدوات الصيا}

وفي حقيقة الأمر ارتبطت الأسلحة التى استخدمها الإنسان فى صيد

الحيوانات أو صراعه مع منافسيه، ارتبطت بمناظر أخرى غير ذللك، ففي الجبة منظر لسبع سيدات: ستة منهن فى اتجاه واحد والسابعة مقابلة لهن، وتمسك ثلاثة منهن بأقواس وكأنهن جميعًا يقمن برقصة دينية

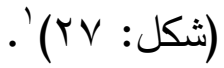

${ }^{1}$ Majeed Khan, Rock Art of Saudi Arabia, Arts 2, (2013), p.451. 


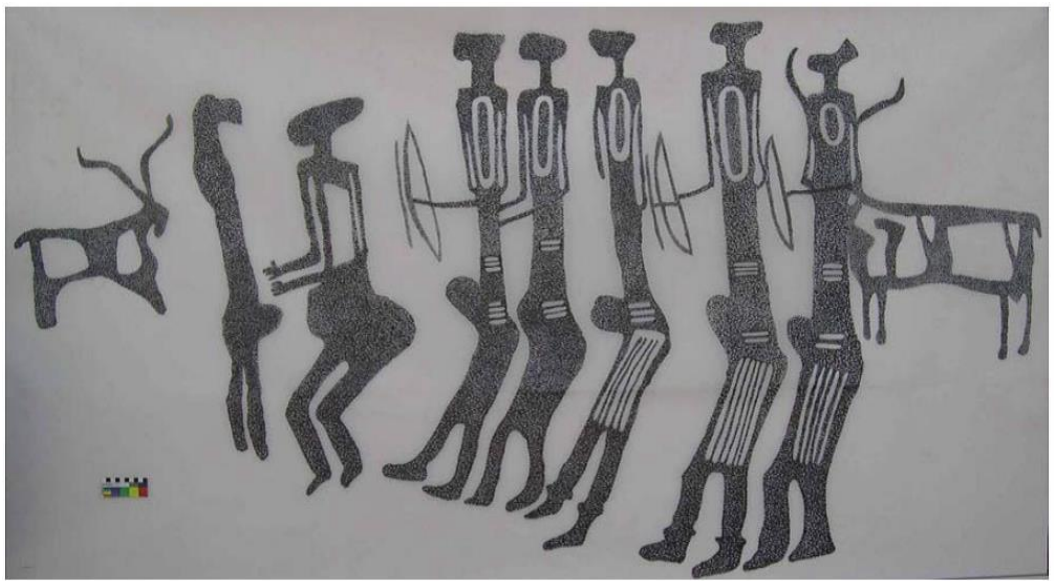

(شكل: (rV ) منظر لرقصة دينية

Majeed Khan, Rock Art of Saudi Arabia, Arts 2, (2013), fig.4.

ومنظر أخر بنجران لسبع سيدات يقمن برقصة، إحداهن تمسك

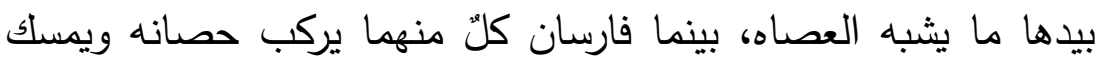

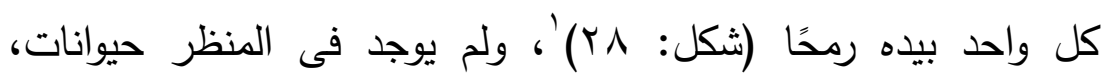
فبالتالي تفسير وجود رمح للاحتفال وليس للصيد.

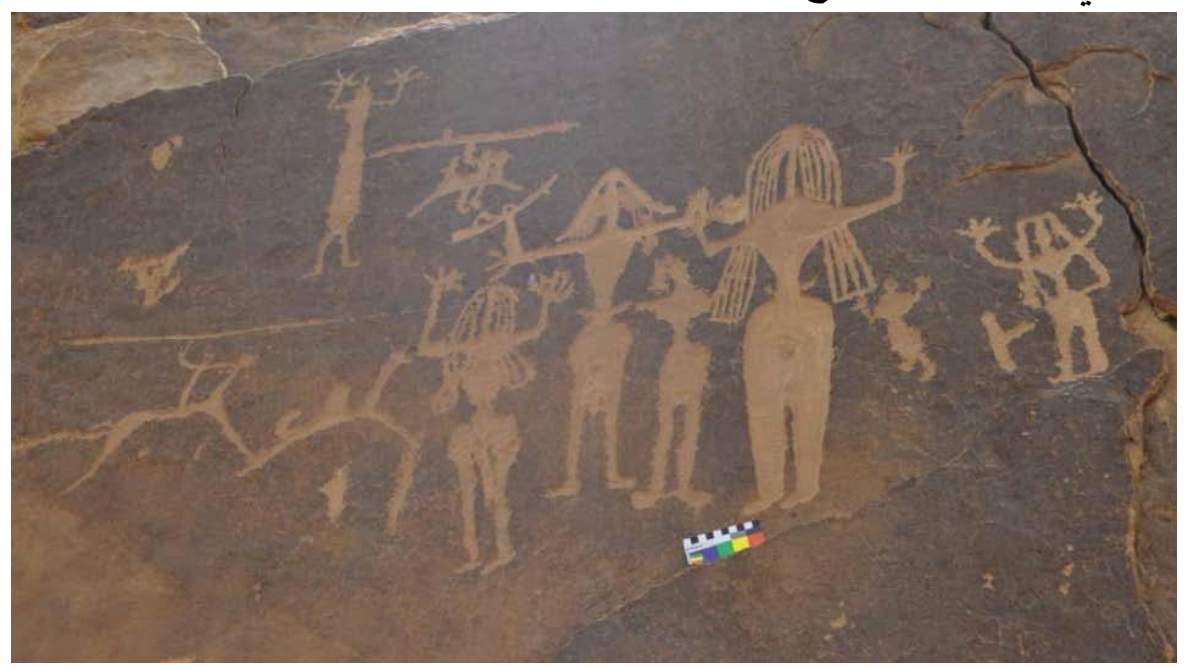

(شكل: ( ) رقص دينى

Majeed Khan, Rock Art of Saudi Arabia, Arts 2, (2013), fig.31.

${ }^{1}$ Majeed Khan, Rock Art of Saudi Arabia, Arts 2, (2013), p.469. 


\section{وفي الختام يمكن عرض نتائج البحث على الوجه الآتي:}

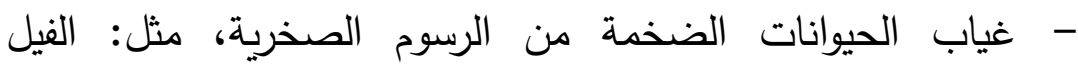

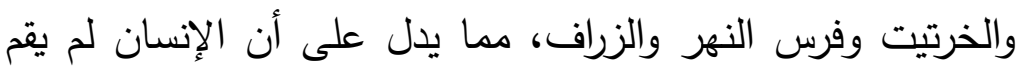
برسم مناظر صيد الحيوانات إلا بعد غياب تلك الحيوانات الضخمة من المملكة العربية السعودية.

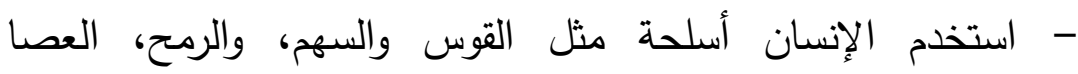

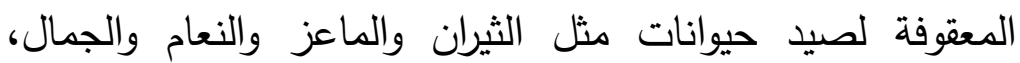
والطيور • - ركوب الجمل واستخدامه فى مطاردة النعام، دون غيرها من

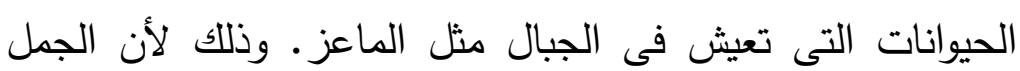
يستطيع أن يطارد الحيوان فى الأرض السهلة والفلوات دون الجبال.

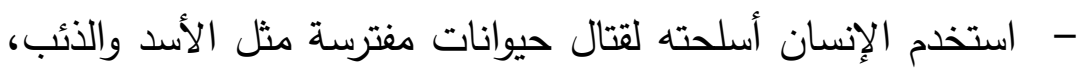
واستخدم القوس والرمح فى صراعه البشري.

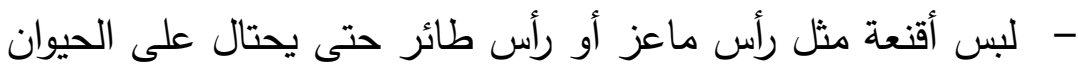
لاصطياده، أو ربما كانت هذه المناظر ذات طابع ديني.

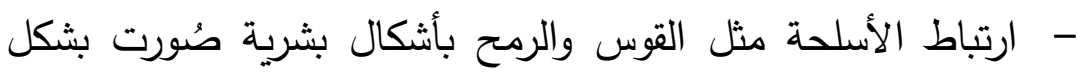
ضخم ربما لتقديسها أو لكونها لزعماء قبائل أو حكام. 


\section{قائمة المصادروالمراجع}

\section{أولاً: المراجع العربية والمعربة:}

ا.رحمة بنت عواد السناني، دراسة وصفية تحليلية لمجموعة من

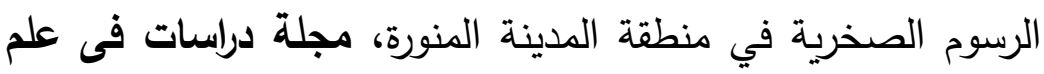

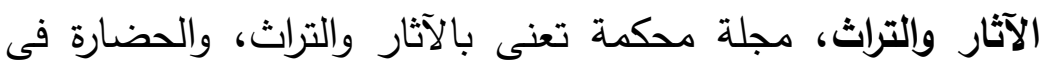

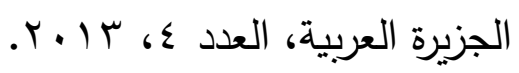

r. عبدالرحمن الكباوى وآخران، تقرير مبدئى عن المرحلة الثانية عن المسح الشامل للنقوش والرسوم الصخرية فى المنطقة الشمالية للعام

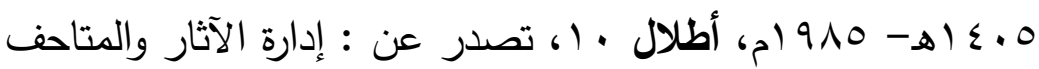

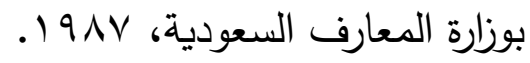
r. عبدالله السعود وآخرون، مسح الرسومات الصخرية والكتابات القديمة

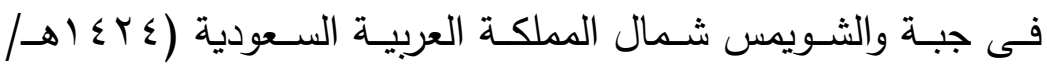

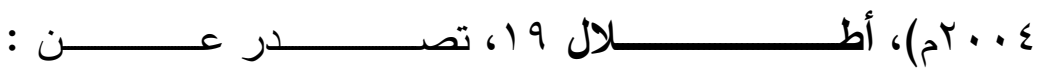

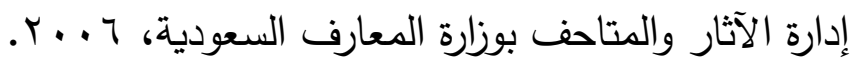

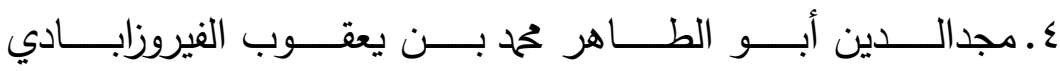

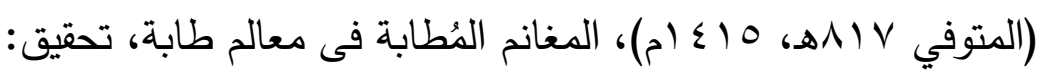
حمد الجاسر، الطبعة الأولى، (الرياض، منشورات دار اليمامة للبحث والترجمة والنشر، 979 ( ) ).

0. مجيد خان، التركيب والثكل فى الرسوم الصخرية فى شمال المملكة العربية السعودية، أطلال |ل، تصدر عن: وكالة الآثار والمتاحف

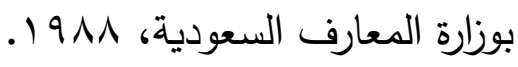
7. مجيد خان دراسة تحليلية للطقوس الدينية القديمة فى المنطقة الثالمية من خلال الرسوم الصخرية، أطلال بال ا، تصدر عن: وكالة

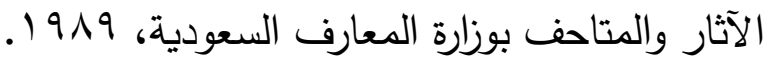


V. مجيد خان حسن خـان، دراسـة نقديـة عن كتب أناتي فى الرسوم

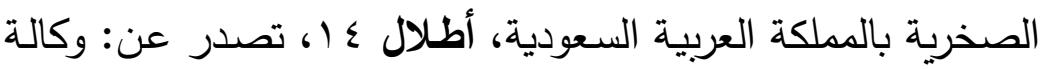

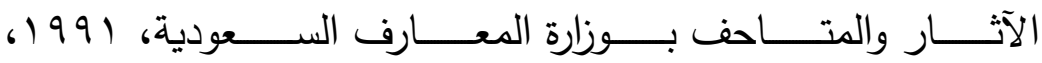

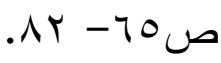

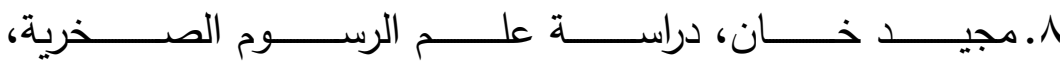
(الرياض، مكتبتنا العربية، V. V. (Y).

9. محمد عبدالمنعم، آثار ما قبل التاريخ وفجره في المملكة العربية السعودية، ترجمة: عبدالرحيم ححمد خبير، تقديم: عبدالرحمن الطيب الأنصاري، (الرياض: مؤسسة الجريسي للتوزيع والإعلان، 1990 (1).

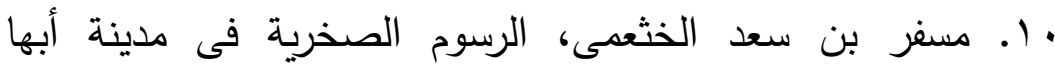

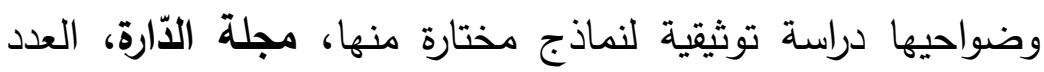

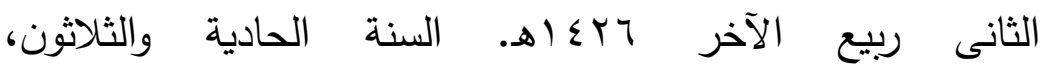

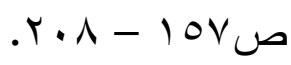

ا(1. مسفر بن سعد بن محم الخثعى، موسوعة الآثار والتراث والمعالم

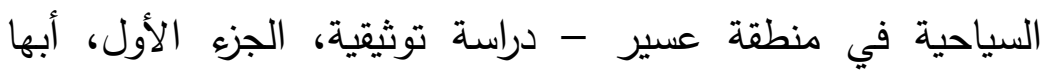
والمراكز التابعة لها، (جامعة الملك خالد، مكتبة الملك فهد الوطنية،

$$
\text { . (ه) } \leq r q
$$

r ا. مسفر بن سعد بن محم الخثعىى، موسوعة الآثار والتراث والمعالم السياحية في منطقة عسير - دراسة توثيقية، الجزء الثامن، تتليت، (جامعة الملك خالد، مكتبة الملك فهد الوطنية، 9 ـ أهـ). با (.نبيل يوسف الثيخ يعقوب، الرسومات الصخرية في المنطقة

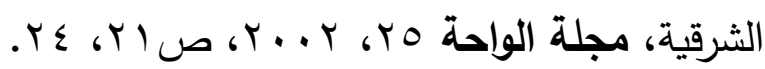
ـ ا. نورمان م. والين وآخرون، مجموعة من المواقع فى جدة ووادى الهى فاطمة، أطلال 11، تصدر عن : إدارة الآثار والمتاحف بوزارة

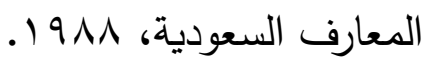


1 . يوريس زارينس وأخرون، التقرير المبدئى عن مسح المنطقتين

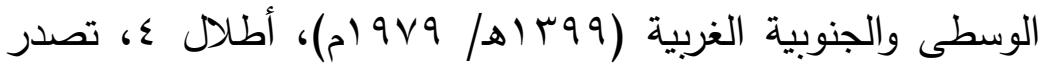
عن : إدارة الآثار والمتاحف بوزارة المعارف السعودية، . 191. 17 ا. يوريس زارينس وآخران، برنامج المسح الأثرى الثامل لأراضى الثى

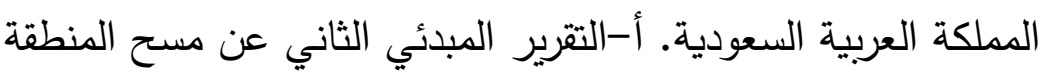
الجنوبية الغربية، أطلال 0، تصدر عن: وكالة الآثار والمتاحف

$$
\begin{aligned}
& \text { بوزارة المعارف السعودية، ال191 ـ. } \\
& \text { ثانيًا: المراجع الأجنبية }
\end{aligned}
$$

17. Adam. L., Primitive Art, London, 1963.

18. Anati. E., Rock Art in Central Arabia, vol.1 (1968).

19. Bednarik. R. G and Khan. M., Scientific Studies of Saudi Arabian Rock Art, Rock Art Research 2005 - Volume 22, Number 1, pp. 49-81.

20. Červíček. P., Some African Affinities of Arabian Rock Art, Rassegna di Studi Etiopici, Vol. 27 (1978-1979), pp. 5-12.

21. Clarke. C., Rock Art at Jubba, Northern Saudi Arabia, Proceedings of the Seminar for Arabian Studies, Vol. 9, Proceedings of the Twelfth SEMINAR FOR ARABIAN STUDIES held at the School of Oriental \& African Studies and Institute of Archaeology, London on 10th - 12th July, 1978 (1979), p. 80.

22. Howe. B., "Two Groups of Rock Engravings from the Hijā"z, Journal of Near Eastern Studies, Vol. 9, No. 1 (Jan., 1950), pp. 8-17.

23. Groucutt. H. S and Petraglia. M. D., The Prehistory of the Arabian Peninsula: Deserts,Dispersals, and Demography, Evolutionary Anthropology 21(2012), pp.113125. 
24. Jennings. $\mathrm{R}$ and others., High-resolution geospatial surveying techniques provide new insights into rock-art landscapes at Shuwaymis, Saudi Arabia, Arab. arch. Epig 25 (2014), pp. 121.

25. Majeed Khan, Recent Rock Art and Epigraphic Investigations in Saudi Arabia, Proceedings of the Seminar for Arabian Studies, Vol. 21, Proceedings of the Twenty Fourth SEMINAR FOR ARABIAN STUDIES held at Oxford on 24th 26th July 1990 (1991), pp. 113-122.

26. Majeed Khan, A Critical Review of Rock Art Studies in Saudi Arabia, East and West, Vol. 48, No. 3/4 (December 1998), pp. 427-437.

27. Majeed Khan, Rock Art of Saudi Arabia, Arts 2, (2013), pp.447-475.

28. Ryckmans. J., "An Ancient Stone Structure for the Capture of Ibex in Western Saudi Arabia", Proceedings of the Seminar for Arabian Studies, Vol. 6, Proceedings of the Ninth SEMINAR FOR ARABIAN STUDIES held at The School of Oriental \& African Studies and the Institute of Archaeology, London on 7th-9th July, 1975 (1976), pp. 161-165.

29. Thompson. C., Rock Engravings Near Madinah, Saudi Arabia, Proceedings of the Seminar for Arabian Studies, Vol. 5, Proceedings of the Eighth SEMINAR FOR ARABIAN STUDIES held at The Oriental Institute, Oxford on 3rd-5th July, 1974 (1975), pp. 22-32.

30.Zarins. J., Early Rock Art of Saudi Arabia, Archaeology, Vol. 35, No. 6 (November/December 1982), pp. 20-27. 


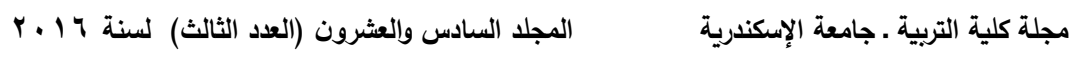

\section{المواقع الاكترونية: - (الكتية}

صالح بن محم المطيرى، تقرير عن وادي الصويدرة بمنطقة المدينة

$$
\text { المنورة }
$$

http://www.altorthalatiq.com/vb/showthread.php?t=1428\&highlight

$$
\text { المخلص }
$$

عرفت المملكة العربية السعودية الفن الصخري فى فترة ما قبل الكتابة وهو عبارة عن رسوم ونقوش لأشكالٍ حيوانية وبشرية، واستمر وجود الفن الصخري بالمملكة بعد معرفة الإنسان للكتابة.

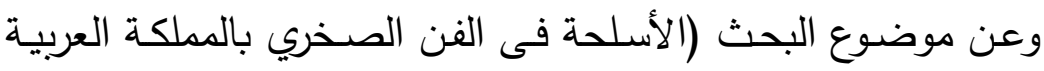
السعودية)؛ فلقد استخدم إنسان الفن الصخري بالمملكة العربية السعودية 


$$
\begin{aligned}
& \text { أسلحة مثل القوس والسهم، والرمح، والعصا المعقوفة لصيد حيوانات مثل } \\
& \text { الثيرات والماعز والنعام والجمال والطيور ، وذلك للحصول على غذئه وائهـ } \\
& \text { من تلك الحيوانـات. واستعان بالجمل بعد ترويضـه ليركب على ظهره }
\end{aligned}
$$

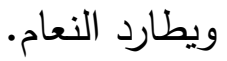

$$
\begin{aligned}
& \text { واستخدم القوس والسهم، والرمح فى صـراعه البشرى، وأيضًا ارتبط }
\end{aligned}
$$

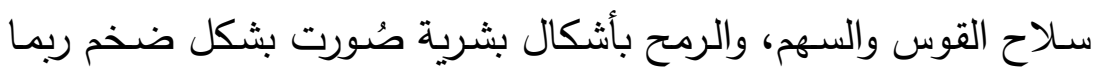

$$
\begin{aligned}
& \text { لتقديسها أو لكونها زعماء قبائل أو حكام. }
\end{aligned}
$$

\section{Abstract}

The Kingdom of Saudi Arabia knows rock art in the pre-writing period, which consisted of a painting and inscriptions for animals and human forms. The existence of the rock art continued in the Kingdom after the human knowledge of writing.

According to the subject of my research (The weapons in the Rock Art of the Saudi Arabia Kingdom); it dealt with weapons such as the bow and arrow, spear, Boomerang all of which used by hunters to catch Ox, goats, ostriches, camels and birds to get his food. Men of this period used another way of hunting which is tamed camel to ride for chasing ostriches.

Beside that bow and arrow, and a spear weapons used in the human struggle, and also connected with human forms depicted hugely, perhaps for being consecrated or for being leaders of the tribes or rulers of big areas. 